\title{
The Aryl Hydrocarbon Receptor: A Key Bridging Molecule of External and Internal Chemical Signals
}

\author{
Jijing Tian, ${ }^{\dagger}+$ Yu Feng, ${ }^{\dagger}$ Hualing Fu, ${ }^{\dagger}$ Heidi Qunhui Xie, ${ }^{\dagger}$ Joy Xiaosong Jiang, ${ }^{*},{ }^{\ddagger}$ and Bin Zhao ${ }^{\dagger}$ \\ ${ }^{\dagger}$ Research Center for Eco-Environmental Sciences, Chinese Academy of Sciences, Beijing 100085, China \\ ${ }^{\ddagger}$ Department of Internal Medicine, Gastroenterology and Hepatology, University of California, Davis, Sacramento, California 95817, \\ United States
}

ABSTRACT: The aryl hydrocarbon receptor $(\mathrm{AhR})$ is a highly evolutionary conserved, ligand-activated transcription factor that is best known to mediate the toxicities of dioxins and dioxin-like compounds. Phenotype of AhR-null mice, together with the recent discovery of a variety of endogenous and plant-derived ligands, point to the integral roles of AhR in normal cell physiology, in addition to its roles in sensing the environmental chemicals. Here, we summarize the current knowledge about AhR signaling pathways, its ligands and AhRmediated effects on cell specialization, host defense and detoxification. AhR-mediated health effects particularly in liver, immune, and nervous systems, as well as in tumorgenesis are discussed. Dioxin-initiated embryotoxicity and immunosup-

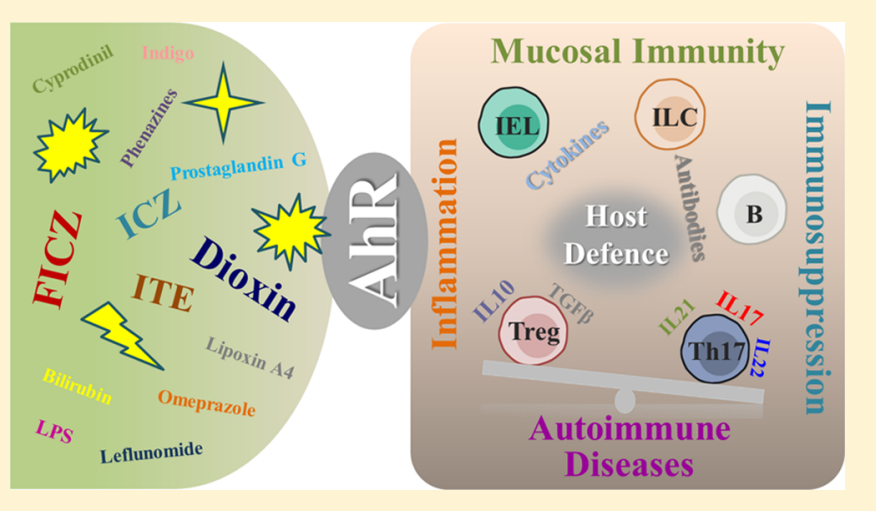
pressive effects in fish and birds are reviewed. Recent data demonstrate that AhR is a convergence point of multiple signaling pathways that inform the cell of its external and internal environments. As such, AhR pathway is a promising potential target for therapeutics targeting nervous, liver, and autoimmune diseases through AhR ligand-mediated interventions and other perturbations of AhR signaling. Additionally, using available laboratory data obtained on animal models, AhR-centered adverse outcome pathway analysis is useful in reexamining known and potential adverse outcomes of specific or mixed compounds on wildlife.

\section{INTRODUCTION}

The aryl hydrocarbon receptor (AhR) is a ligand-activated transcription factor that belongs to the basic helix-loop-helix Per-Arnt-Sim (bHLH/PAS) superfamily, whose members play key roles in gene expression networks that underly many essential physiological and developmental processes, particularly those involved in responding to environmental signals such as oxygen gradients and low molecular weight chemicals. ${ }^{1-5}$ Studies on AhR, to understand the toxicological effects of TCDD have been conducted for over 30 years. ${ }^{6,7}$ Since then, kinds of environmental AhR agonists including halogenated hydrocarbons (HAHs) and polycyclic aromatic hydrocarbons (PAHs), which were synthetic in nature and introduced into the environment by industrial production, have been identified. Toxicological consequences mediated by AhR in response to dioxins, included impairments in development, fertilization, reproduction, endocrine, nervous, and immune systems, as well as in carcinogenesis, were reported. ${ }^{8-13}$ There have been many excellent reviews about the exogenous ligands of AhR, and this topic will not be discussed in detail here. ${ }^{14,15}$ Study on AhR knockout (KO) mice indicated that AhR deficiency impaired several physiological progresses such as the development of immune system. ${ }^{16,17}$ In accord with the conserved roles of AhR in physiology and development, a variety of endogenous $\mathrm{AhR}$ ligands have been recently identified. $^{18-21}$ To date, physiological roles of $\mathrm{AhR}$ in cancer promotion, autoimmune diseases, and liver diseases have been reported. $^{22-26}$ Thus, AhR is undoubtedly a key protein that mediates both toxicological and physiological effects upon sensing exogenous and endogenous chemicals.

$\mathrm{AhR}$ is present in a variety of organisms and has been demonstrated to be highly conserved during hundreds million years of evolution. ${ }^{4}$ This high degree of conservation is in accord with the important function of $A h R$ in both physiological and toxicological processes. AhR diversity among species may underlie specie-specific sensitivity to dioxin effects, as well as potential specification in the physiological roles of AhR itself. ${ }^{12}$ Although roles of AhR in toxicology of dioxin or dioxin-like compounds (DLCs) have been thoroughly investigated in laboratory studies using murine models, data available for AhR-mediated effects or toxicity on other species are very limited. Despite specie-differences among fish, birds, and mammalians, several biological functions in early vertebrates, especially the immune responses, are conserved and share common features with that in mammalians during

Received: February 13, 2015

Revised: June 14, 2015

Accepted: June 16, 2015

Published: June 16, 2015 
evolution, ${ }^{27}$ in which AhR may be involved. Thus, data on the role of AhR from the mammalian studies will also be helpful to further elucidate AhR-mediated effects in response to dioxins in the ecological risk assessment.

In this review, recently identified natural AhR agonists and their effects in cell differentiation, host defense and detoxification were summarized. AhR-mediated health effects particularly on immune and nervous systems, and on liver, as well as their connection with tumorgenesis were also reviewed, with an emphasis on AhR as a sensor of chemical signals that include diverse exogenous and endogenous ligands from both external and internal environments. Furthermore, dioxininitiated toxic effects such as embryotoxicity and immunosuppressive effects on wildlife species including fish and birds were considered in this review. This summary will provide new perspectives on AhR-mediated risk assessment in wildlife populations and in humans, and provide the insights on how dioxins or DLCs hijack the AhR and disrupt AhR-dependent signaling pathways to produce toxicity.

\section{DIVERSITY OF AHR LIGANDS}

$\mathrm{AhR}$ as a ligand-dependent protein is well-known for its participation in the toxic effects of dioxins. The AhR signaling pathway in dioxin toxicity has been investigated in depth for decades. ${ }^{2,15}$ In the absence of ligand stimulation, AhR resides in the cytoplasm and, per binding a ligand, translocates to a nucleus where it makes a complex with an obligatory heterodimer partner aryl hydrocarbon receptor nuclear translocator (ARNT), to become fully competent to bind the promoter element of the target genes. In the nucleus, AhR binds to a core nucleotide sequence $5^{\prime}$-TNGCGTG-3', termed a dioxin response element (DRE). DRE elements occur frequently in the mammalian genome, and are also present in the promoters of genes that encode many xenobiotic metabolizing enzymes as well as cytokines IL10, IL21, IL17A/F, IL22, and ROR $\gamma$ t, which are the effector molecules or transcriptional factor of Tregs, Th17 cells or innate lymphoid cells (ILCs). ${ }^{26,28}$ Evidence so far suggests an important role for $\mathrm{AhR}$ in the development and differentiation of lymphocytes. Because regulation of AhR function by endogenous ligands is poorly understood, their specific roles in AhR-mediated responses in physiological and pathological conditions still remain to be elucidated. Here we summarize the most common AhR ligands and discuss their effects with the focus on cell differentiation, host defense and detoxification (Figure 1).

In addition to the known synthetic ligands, such as HAHs and PAHs, various endogenous and plant-derived natural ligands of AhR have been recently identified and demonstrated to play critical roles in normal physiological functions. The most ubiquitous and best studied compounds are tryptophan and its metabolites, such as 6-formylindolo-(3,2-b)-carbazole (FICZ) and 2-( $1^{\prime} \mathrm{H}$-indole- $3^{\prime}$-carbonyl)-thiazole-4-carboxylic acid methyl ester (ITE). ${ }^{18,20,29}$ Indoxyl sulfate (IS) is an indole metabolites shown to be a potent $\mathrm{AhR}$ agonist in human primary hepatocytes (in nanomolar concentrations). ${ }^{21}$ It was also reported to enhance NAPDH oxidase 4 (NOX4) and monocyte chemoattractant protein-1 (MCP-1) expression in human umbilical vein endothelial cells (HUVECs), thereby indicating roles of AhR in atherogenesis. ${ }^{30}$ ITE is another endogenous commonly present AhR ligand that was recently identified. ${ }^{18}$ ITE and TCDD-induced gene responses in mouse primary lung fibroblasts were remarkably similar, including

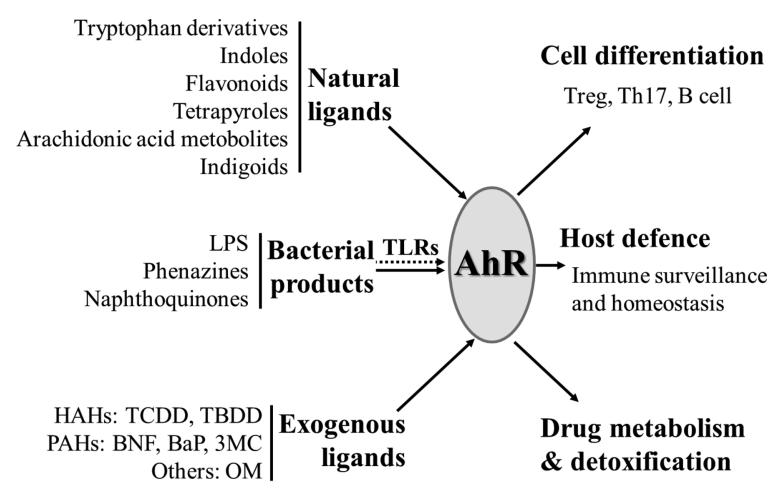

Direct activation $\longrightarrow$ Indirect activation $\quad \cdots . .$.

Figure 1. AhR agonists and emerging functions of $\mathrm{AhR}$ as a sensor. AhR is involved in metabolism and regulates genes that are involved in detoxification of classical ligands, such as TCDD and BNF. Newly defined ligands from dietary/endogenous components or bacterial products are indicated to be important in the immune system for cell differentiation and immune privilege.

induction of AhR-dependent xenobiotic-metabolizing enzymes such as Aldh3al and Cyplal (>500-fold), as well as AhRR (116-fold). ${ }^{31}$ ITE also plays a role in inhibiting proliferation of cancer cells. It suppressed in vitro proliferation of human ovarian cancer cells, OVCAR-3, and SKOV-3 migration via the AhR dependent pathway. ${ }^{32}$ In a model of mice experimental autoimmune encephalomyelitis (EAE), daily oral administration of ITE $(200 \mu \mathrm{g} /$ mouse $)$ suppressed EAE through activation of Foxp $3^{+}$Tregs, and the effect was blocked in $\mathrm{AhR}^{\mathrm{d}}$ mice, that codes for a low affinity AhR allele. ${ }^{33}$ FICZ is a tryptophan oxidative product produced by exposure to ultra violet (UV) and visible light, with high levels in cell culture medium that contributes to background AhR activation. ${ }^{34}$ Being both AhR high affinity agonist and a substrate for cytochromes Cypla1/1a2 and 1b1, FICZ is involved in the autoregulatory loop that keeps its own concentration low. Inhibition of Cyp 1a1 activity slowed intracellular metabolism of FICZ and enhanced FICZ-dependent transcription of the Cyplal gene and EROD activity. ${ }^{35}$ Exposure to FICZ markedly down-regulated inflammatory cytokines and induced IL22 expression in trinitrobenzenesulfonic acid (TNBS), dextran sulfate sodium (DSS) induced colitis in mice. Consistently, expression of AhR in intestinal tissue from inflammatory bowel disease (IBD) patients was significantly reduced. ${ }^{36}$ In accord with the hypothesized existence of aromatic acid-derived endogenous ligands for $\mathrm{AhR}$, cell culture medium such as Iscove's modified Dulbecco's medium (IMDM), which is rich in tryptophan, tyrosine, and phenylalanine, promoted differentiation of $\mathrm{CD}^{+} \mathrm{T}$ cells to Th17 in an AhR-dependent manner, whereas RPMI1640 containing less such AhR ligands, exhibited very low levels of Th17 polarization. ${ }^{37}$ There are also some chemicals that could be both AhR agonists and antagonists, such as flavonoids. ${ }^{38,39}$ The pathophysiological roles of the natural ligands other than tryptophan-derived chemicals, such as bilirubin and biliverdin, indigo, lipoxin A4, prostaglandin G, indolo(3,2-b)carbazole (ICZ), indole acetic acid (IAA), which are endogenous and/or dietary-derived, need to be further elucidated. ${ }^{40-42}$ Of note, some newly defined exogenous AhR activators, including cyprodinil, leflunomide, omeprazole are widely used in agriculture or as pharmaceuticals, and as such, should be investigated for their potential interference with the AhR signaling pathway. ${ }^{43-45}$ 
Previous studies have shown AhR is crucial for controlling bacterial infections while AhR-deficient mice were highly susceptible to infection with Citrobacter rodentium. ${ }^{46,47}$ ROR $\gamma \mathrm{t}^{+}$ILCs and related cytokine IL22 expression were reduced in AhR-deficient mice, and this is thought to contribute to Citrobacter rodentium infection in both studies. ${ }^{46,47}$ In accord with these studies, a naturally derived AhR agonist tryptophan metabolite phytochemical indole-3-carbinol (I3C) was reported to contribute to the maintenance of intestinal intraepithelial lymphocytes (IELs) that also serve to protect the gut epithelium from bacterial infection. ${ }^{25}$ Indole, a major bacterial metabolite in the intestinal tract, was demonstrated to be an AhR antagonist in physiological concentrations. ${ }^{48}$ In the presence of tryptophan, an indole derivatives, indole-3-aldehyde (IAld), was observed both in broth cultures and supernatants from ex vivo stomach of Ido $1^{-/-}$mice exposed to lactobacilli. ${ }^{49}$ The same study demonstrated that lactobacilli-produced IAld improved resistance of mice to fungal infections via AhRdependent IL22 expression. Thus, microbiota and the putative AhR ligands produced by them in gastrointestinal tracts play critical roles in protection of local tissues from infections. The microbiota-AhR-IL22 axis is worth further investigation in host resistance due to its potential importance in Crohn's disease, inflammatory bowel disease (IBD) and so on.

Additional roles of $\mathrm{AhR}$ in host defense by sensing the bacterial products were recently reported. Moura-Alves and colleagues found that bacterial pigmented virulence factors, such as phenazine pyocyanin (Pyo) from P. aeruginosa and naphthoquinone phthiocol (Pht) from $\mathrm{M}$. tuberculosis, act as direct AhR ligands. ${ }^{50}$ In this study in silico, molecular modeling analysis predicted that similar structural features of these bacterially produced AhR ligands to that of TCDD. In subsequent experiments, the authors further found that bacterial pigments significantly induced AhR-dependent luciferase activity in a reporter cell line, and increased Cyp1a1, Cyp1b1, and AhRR mRNA levels, while the induction was decreased after in AhR KO cells. Knockdown of AhR significantly reduced Pyo and Pht degradation, indicating an AhR dependent role in degradation of bacterial pigments. Further, animal experiments showed that $\mathrm{AhR}^{-/-}$mice were more susceptible to $\mathrm{P}$. aeruginosa infection and had significant increased bacterial loads in liver and spleen. Induction of proinflammatory cytokines such as $\operatorname{IL} 1 \beta$ and recruitment of neutrophils were confirmed to contribute to AhR-mediated defense against bacterial infections. In agreement with this study, a role of AhR in host tolerance was also addressed experimentally using mice exposed to lipopolysaccharides (LPS).$^{51}$ LPS are the major constituents of the Gram-negative bacterial outer membranes and act as extremely strong stimulators of innate immunity. ${ }^{52}$ The authors further showed that AhR activation in LPS-challenged mice occurred in an indoleamine 2,3-dioxygenase 1 (IDO1)-dependent manner. ${ }^{51}$ Thus, AhR serves as a direct or indirect sensor in bacterial infections and promptly triggers natural and innate defense mechanisms by induction of inflammatory cytokines and chemokines to local sites of infection. These recent findings summarized above extend the list of AhR ligands to bacterial virulence factors and provide evidence for additional roles of AhR signaling in surveillance. However, how AhR pathway protects the host against bacterial infection still needs to be determined. Physiological roles of AhR in T cell differentiation and maintenance of ILCs, as well as in the pathways utilized by the proinflammatory and anti-inflammatory cytokines secreted in AhR-dependent manner should be considered when interpreting the roles of $\mathrm{AhR}$ in bacterial infections.

\section{AHR-MEDIATED HEALTH EFFECTS}

AhR-mediated health effects in immune system, liver, nervous system and tumorgenesis, were subjects of intensive studies in recent years. The immune system is a sensitive target for the AhR-mediated signaling pathway. Immunosuppressive effects of dioxin were observed not only in experimental model animals but also in wildlife and in humans under environmentally relevant concentrations. ${ }^{53-55}$ Knockout animal studies and identification of gut microbiota-derived and endogenous ligands of AhR point to critical physiological functions for AhR in immune system, especially in proliferation, differentiation of immune cells and organogenesis of intestinal lymphoid follicles. ${ }^{16,17,46,56}$ There are also a body of new evidence indicating that $\mathrm{AhR}$ is involved in hepatic fibrogenesis, steatosis, autoimmune hepatitis (AIH), as well as neurotransmission impairment. ${ }^{57-59}$ Additionally, new data elucidating roles of $\mathrm{AhR}$ in the innate and the adaptive immunity, and urinary systems as well as eye diseases, will be summarized below.

AhR is Required for Tregs/Th17 Cell Differentiation. Helper $\mathrm{T}$ cells and Tregs play critical roles in the balance of autoimmune and allergic diseases, such as EAE, rheumatoid arthritis and asthma. ${ }^{33,60,61}$ Effects of AhR on the differentiation and function of $\mathrm{T}$ cells, especially the $\mathrm{CD}^{+} \mathrm{T}$ cells were extensively studied. ${ }^{62,63}$ These studies found that a reciprocal relationship exists between the production of anti-inflammatory Foxp $3^{+}$Treg cells and pro-inflammatory $\mathrm{T}$ helper cells secreting IL17 (Th17). Recent investigations suggested that AhR plays a critical role in maintenance of this balance. Both Treg and Th17 cells exhibit high levels of AhR expression consistent with evidence showing that $\mathrm{AhR}$ is a key transcription factor for Treg and Th17 differentiation (Figure $2)^{26,64}$ As such, in the experiment where $T$ cells were polarized

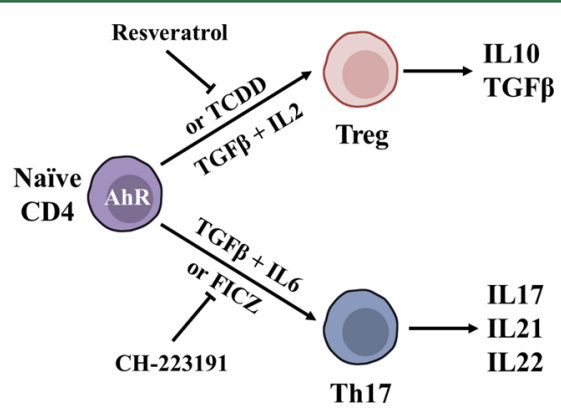

Figure 2. Roles of AhR in $\mathrm{T}$ cell differentiation. TGF $\beta$, together with IL2 or IL6, induces Treg or Th17 cells to produce cytokines in tolerance and immunity while TCDD or endogenous AhR ligand could induce the same effects as TGF $\beta$ on naïve $\mathrm{CD} 4^{+} \mathrm{T}$ cells. On the other hand, AhR inhibitor/antagonist or AhR deficient mice display diminished impacts on $\mathrm{T}$ cell differentiation.

for $24 \mathrm{~h}$, Treg differentiation-promoting condition (TGF $\beta 1$ ) induced a 4-fold increase and Th17 differentiation-promoting condition (TGF $\beta 1$ plus IL6) induced a 78-fold increase, correspondingly, in AhR expression. ${ }^{65}$ Consistent with this observation, AhR deficient mice displayed decreased number of Tregs, while in response to the stimulation by myelin oligodendrocyte glycoprotein $\left(\mathrm{MOG}_{35-55}\right.$, an immunogenic epitope that could induce EAE in rodents) the AhR null mice 
developed increased EAE severity, displayed increased number of Th17 cells, tracking with the levels of corresponding proinflammatory cytokines. ${ }^{64}$ Thus, the AhR pathway is important in $\mathrm{T}$ cell differentiation, particularly in the balance of Tregs and Th17 cells.

Importantly, further investigations showed that AhRmediated regulation of the generation of Treg and Th17 cells was in a ligand-specific manner. ${ }^{64}$ The authors found that AhR activation by TCDD triggered the conversion of $\mathrm{CD} 4^{+} \mathrm{Foxp}^{-}$ $\mathrm{T}$ cells to functional Treg cells, while treatment with the AhR antagonist resveratrol interfered with the induction of Treg cells. However, FICZ, a natural AhR ligand, inhibited conversion of $\mathrm{CD}^{+} \mathrm{Foxp}^{-} \mathrm{T}$ cells into $\mathrm{CD} 4^{+} \mathrm{Foxp}^{+}$Tregs and promoted Th17 cell differentiation. Another study also showed that TCDD treatment decreased the number of $\mathrm{CD} 4^{-} \mathrm{CD} 8^{-}, \mathrm{CD}^{+} \mathrm{CD}^{+}, \mathrm{CD} 4^{+} \mathrm{CD} 8^{-}$, and $\mathrm{CD} 4^{-} \mathrm{CD} 8^{+}$precursor $\mathrm{T}$ cells, but not the number of thymic $\mathrm{CD}^{+} \mathrm{CD} 25^{+} \mathrm{Foxp}^{+}{ }^{+}$Treg cells. ${ }^{66}$ Additionally, the activation of AhR by FICZ during Th17 cell development markedly increased the corresponding production of Th17 T cells and the production of cytokines including $\mathrm{IL} 17$ and IL22. ${ }^{26}$ Moreover, treatment with the AhR antagonist CH-223191 induced impairment in Th17 differentiation with attenuated IL17 production and completely diminished IL22 production. ${ }^{37}$ TCDD had a dose-dependent suppressive effect on EAE induction via $\mathrm{AhR}$ activated Tregs, while $\mathrm{CD} 4^{+} \mathrm{Foxp}^{+}{ }^{+}$Treg levels did not increase in naturally less TCDD-sensitive $A_{h}{ }^{d}$ mice. ${ }^{64}$ Further studies demonstrated direct AhR interaction with, and transactivation of, Foxp3, a transcription factor critical for the development of both inducible and natural Tregs. ${ }^{64}$ From these results we can infer that both persistent xenobiotics and endogenous ligands could affect physiological and pathological functions in the immune system via the signaling pathways direct or indirect regulated by AhR. Thereby, AhR, via different transcriptional partners and pathways, may have pivotal roles for the generation and transformation of different types of $\mathrm{T}$ helper cells, which are related to many autoimmune and hypersensitivity diseases. AhR ligands may represent cofactors in the development of autoimmune diseases ${ }^{26}$ and might be potential drugs for therapy. Further research should be conducted to reveal the interactions between AhR and other transcriptional factors in certain cellular contexts. Modulation of AhR signaling pathway upon exposure to various ligands should also be further investigated to elucidate the mechanisms underlying the ligand-specific responses.

AhR Participates in Mucosal Immunity. IELs and ILCs are two predominant cell types in the mucosal immune system (MIS). Mucosa is the first physical barrier to pathogens and toxins that enter the body through skin, respiration or diet. These immune cells, as a network, protect the mucosal surface from invaders and maintain local homeostasis. Widespread expression of AhR in cell types of the barrier surface highlights its primary function in sensing environmental signals. For example, AhR is activated by ultraviolet rays (UVR) and the agonist 4-n-nonylphenol (NP), while 3-methoxy-4-nitroflavone (MNF), an AhR antagonist, reduced UVR-mediated immunosuppression and the induction of Treg in murine contact hypersensitivity (CHS) model. ${ }^{67}$ This data indicates a critical role of AhR in mediating UVR-induced immunosuppression. However, pathways for AhR activation under human physiological condition are still not fully elucidated. Animal and in vitro studies showed that AhR deficiency leads to decreased numbers of ROR $\gamma \mathrm{t}^{+}$ILCs in the gut, suggesting that
AhR plays an essential role in ROR $\gamma \mathrm{t}^{+}$ILC maintenance and function. ${ }^{47}$ As for IELs, the absence of AhR in the cells does not impair their development, proliferation or migration, but compromises the cell number resulting in exacerbation of microbial load on the gut surface. ${ }^{25}$ To date, several lines of evidence strongly implicate that $\mathrm{AhR}$ is a key regulator of mucosal immunity, through promotion or inhibition of specification of specific types of immune cells and expression and secretion related cytokines. Therefore, AhR is considered to be a sentinel overseeing and safeguarding the survival of immune cells in the gut. ${ }^{68}$

Importance of $\mathrm{AhR}$ for the function of IELs is demonstrated by $\mathrm{Li}$ and co-workers who showed that exogenous environmental stimuli maintain intraepithelial lymphocyte numbers in both skin and intestine of mice via AhR activation. ${ }^{25}$ In their study, a particularly high basal expression of AhR in IELs was detected in TCRV $\gamma 3$ and TCRV $\gamma 5$ positive cells. Consistent with this observation, AhR deficient mice exhibited a loss of more than $95 \%$ of TCR $\gamma \delta$ cells in the small intestine, and IELs from both dermis and epidermis of skin showed a distinct decrease in number of TCR $\gamma \delta^{\text {hi }}$ cells. TCR $\alpha \beta^{+} \operatorname{CD} 8 \alpha \alpha^{+}$T cells, the other major population of intestinal IELs characterized by high level of AhR expression, were also significantly reduced in AhR KO mice. However, the proportions and numbers of Tregs and ILCs in the lamina propria of the intestine were not significantly changed in AhR KO mice. Further studies found that AhR-deficient bone marrow failed to reconstitute intestinal IELs. However, lymphocyte-specific deletion of $\mathrm{AhR}$ in intestinal IELs and TCRV $\gamma 3$ cells in the skin were indistinguishable from those in $\mathrm{AhR} \mathrm{KO}$ mice. The same study showed that the proliferative capacity of IELs was not affected in the absence of AhR. Thus, the decreased number of IELs was probably caused by their reduced survival potential. These data demonstrated that the maintenance of IELs depends critically on $\mathrm{T}$ cell intrinsic AhR activity. However, how AhR regulates the proliferation and maintenance of IELs is not yet fully understood. The absence of IELs at the epithelial barrier sites is associated with the increased, susceptibility of the intestine to bacterial infection, resulting in inflammation and epithelial damage. Since AhR activation by dietary components showed to improve intestinal immunopathology, it will be highly desirable to screen a series of diet-derived compounds for maintaining a healthy epithelial barrier. Presently, the links between AhR ligands and gut immunobiology in humans are explored insufficiently and need additional investigations.

ILCs are newly identified members of the lymphoid lineage, which have emerging roles in mediating immune responses and in regulating tissue homeostasis and inflammation. ${ }^{69}$ Based on transcription factor expression and the ability to produce distinct patterns of effector molecules, ILCs can be classified into three groups. ${ }^{70}$ The group 3 ILCs, which express transcription factor $\mathrm{ROR} \gamma \mathrm{t}$, have proved to be important in inducing the postnatal formation of intestinal lymphoid clusters, such as cryptopatches and isolated lymphoid follicles, as well as regulating the epithelial barrier function in the skin and gastrointestinal tracts. ${ }^{46,71}$ Notably, ROR $\gamma \mathrm{t}^{+}$ILCs partially depend upon AhR signaling for their development and function. ${ }^{72}$ Studies showed that $\mathrm{AhR}$ is required for the postnatal expansion of intestinal ROR $\gamma \mathrm{t}^{+}$ILCs and plays an essential role in $\mathrm{ROR} \gamma \mathrm{t}^{+}$ILC maintenance and function in postnatal intestinal lympoid tissues. ${ }^{46,47,73}$ AhR deficiency leads to a decreased number of ROR $\gamma \mathrm{t}^{+}$ILCs in the gut of the postnatal mice, but not in newborns. The loss of AhR, 
subsequently, affected the composition of gut microbiota in adult animals and induced gut inflammation. In addition, the lack of AhR was associated with the marked reduction of intestinal ROR $\gamma \mathrm{t}^{+}$ILCs in $\mathrm{AhR}^{-/-} \mathrm{Rag}^{-/-}$mice, indicating that AhR plays a direct role in the development and function of group 3 ROR $\gamma \mathrm{t}^{+}$ILCs. ${ }^{47}$ Together, these data suggest that the effects of AhR deficiency on ROR $\gamma \mathrm{t}^{+}$ILCs are cell-intrinsic. Notably, dietary derived AhR ligands, especially I3C, that is present in cruciferous vegetables, caused significant upregulation of the size of the ROR $\gamma \mathrm{t}^{+}$ILCs pools in the small intestine. ${ }^{46}$ Furthermore, AhR deficient $\mathrm{CD}^{-}{ }^{-} \mathrm{ROR} \gamma \mathrm{t}^{+}$innate cells expressed fewer antiapoptotic proteins, such as bcl2, indicating that $\mathrm{AhR}$ is important for the survival of gut $\mathrm{ROR} \gamma \mathrm{t}^{+}$ ILCs, and thus reduces the bacterial load and recruitment of other immune cells in mucosa (Figure 3).

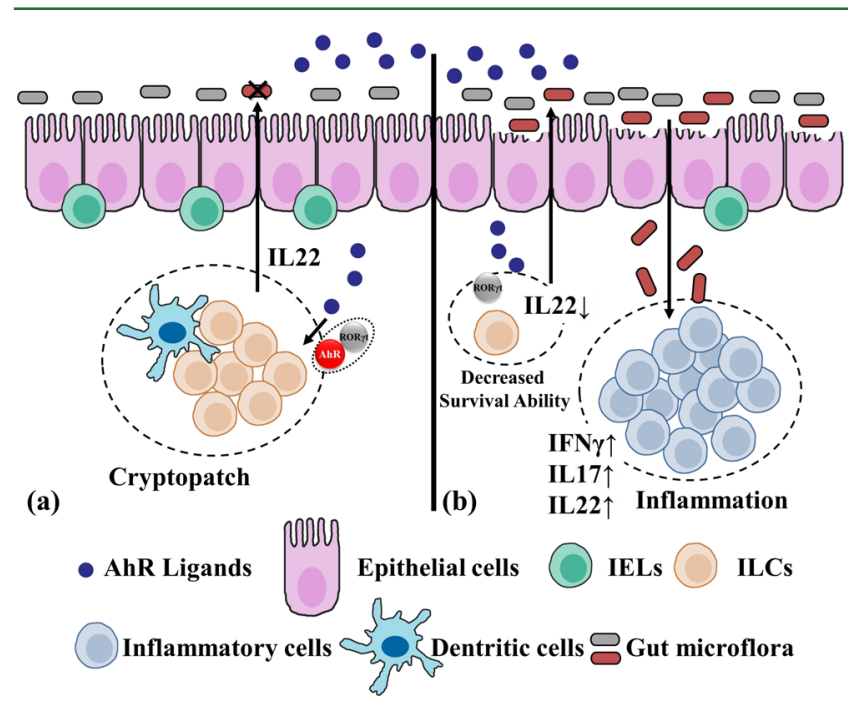

Figure 3. Roles of AhR in gut immunity. (a) With diet-derived AhR ligands, dispersed IELs between epithelial cells and ILCs in cryptopatches are the predominant immune cells that constitute the mucosal immune system. ROR $\gamma \mathrm{t}$ facilitates AhR binding at the IL22 promoter in ILCs, and ILCs-derived IL22 increased epithelial cell survival and production of antimicrobial peptides, thus maintaining intestinal homeostasis and resistance to infections, especially in small intestine and colon. (b) The absence of AhR reduced potential survival of both IELs and ILCs. Diminished cryptopatches resulted in increased bacterial load and epithelial cell damage, and thus recruited inflammatory cell infiltration beneath the mucosa, accompanied by induction of proinflammatory cytokines such as IFN $\gamma$, IL17, and inflammatory cell-derived IL22.

ROR $\gamma \mathrm{t}^{+}$ILCs produce IL22, a cytokine important in defense against intestinal pathogenic infections. In the absence of AhR, production of IL22 decreased markedly reflecting a marked decrease in number of ROR $\gamma \mathrm{t}^{+}$ILCs that evidently resulted in a high susceptibility of mice to the intestinal C. rodentium infection and the associated inflammatory reaction beneath the colon mucosa. ${ }^{46}$ In DSS-induced colitis models, authors showed coexpression of AhR and ROR $\gamma$ t up-regulated IL22 mRNA levels; they also demonstrated a direct interaction between ROR $\gamma \mathrm{t}$ and AhR that apparently facilitated binding of the AhR to the IL22 promoter. $^{36,47}$ Since AhR is a pivotal modulator for intestinal homeostasis, it could be a potential target for the Crohn's disease, the IBD therapy, and the irritable bowel syndrome.
AhR Regulates B Cell Differentiation and Antibody Secretion. In addition to the essential roles of AhR in $\mathrm{T}$ cell biology, recent findings indicate that AhR also plays important roles in B cell differentiation and antibody production. As such, Yoshida and coauthors showed that an endogenous AhR agonist ITE, inhibited expression of IgM, IgG1 and IgE in purified mouse $B$ cells, suggesting that the $B$ cell differentiation into Ig-secreting plasma cells was suppressed. ${ }^{74}$ In another study, exposure to TCDD was reported to alter B cell differentiation and suppress $\operatorname{IgM}$ secretion, the results that were further confirmed by the identification of Bach2 as a direct target of $\mathrm{AhR}^{75}$ This work also showed that Bach2 repressed the expression of the key transcription factor involved in B-cell differentiation, Prdm1. Using siRNA knockdown Bach2, the authors demonstrated about $40 \%$ reversal in the TCDDinduced suppression of IgM secretion. This data showed that the regulation of Bach2 by AhR may be one of the mechanisms involved in the suppression of B cell differentiation by AhR ligands. ${ }^{76}$ It is important to note that, the $\mathrm{B}$ cell cytokine network, in turn, influences $\mathrm{T}$ cell numbers and affects Tregs/ Th1/Th2. ${ }^{77}$ These data clearly indicate that the roles of AhR in immune cell development and differentiation are multi-prong, and involve both direct and indirect interactions between different types of immune cells which should be considered while studying effects of AhR ligands on different aspects of human and animal health.

AhR and Liver Injury. The anatomical feature of the liver makes it the next barrier, after the intestine, on the path of the infectious agents and dietary and environmental xenobiotics. High concentrations of dioxin have been detected in the livers of various species of wildlife. ${ }^{78,79}$ In human epidemiological studies, increased occurrence of hepatobiliary cancer after longterm dioxin exposure was demonstrated. ${ }^{80}$ Hepatocytes express high levels of AhR, which is one of a few key transcriptional regulators that mediate induction of diverse liver cytochrome P450 enzymes by xeno- and endobiotics, thereby liver AhR regulates both nutrient metabolism and xenobiotic detoxification. Consequently, liver AhR was demonstrated to be involved in both adaptive and toxic effects of the dioxin exposure. ${ }^{81}$ Indeed, a role for $\mathrm{AhR}$ in various liver diseases was reported for decades (Figure 4). In the wild type mice studies, subchronic treatment with TCDD induced up-regulation of the fibrogenic pathway and liver fibrosis, while the AhR-null mice exhibited resistance to developing liver fibrosis. ${ }^{22}$ While this finding appears to contradict the phenotype of the AhR-null mice that displayed reduced liver size and exhibited spontaneous liver fibrosis. ${ }^{16}$ The apparent explanation is that TCDD, an AhR agonist, disrupts the intrinsic cellular signaling pathways by inappropriate AhR activation that leads to fibrosis. Notably, when fed with Vitamine A-free diet to induce the condition of retinoid depletion of the liver, the spontaneous fibrosis was reversed and the accompanying collagen deposition were reduced, ${ }^{82}$ suggesting that a hepatic fibrosis in AhR-null mice is probably caused by decreased retinoic acid (RA) metabolism due to down-regulation of Cyp2c39 catalyzed RA catabolism. ${ }^{83}$ Eighty percent of total liver retinols are stored in hepatic stellate cells (HSC) in healthy liver, and metabolites of retinols such as RA have been demonstrated to contribute to liver fibrosis. ${ }^{84}$ Intriguingly, an activation of AhR has also been found in mouse HSCs treated with ethanol. ${ }^{85}$ As such, HSCs treated with ethanol for $6 \mathrm{~h}$ induced AhR translocation and upregulated Cypla1 and Cyp1b1 mRNA levels in a dosedependent manner. Activation of HSCs is significant in 


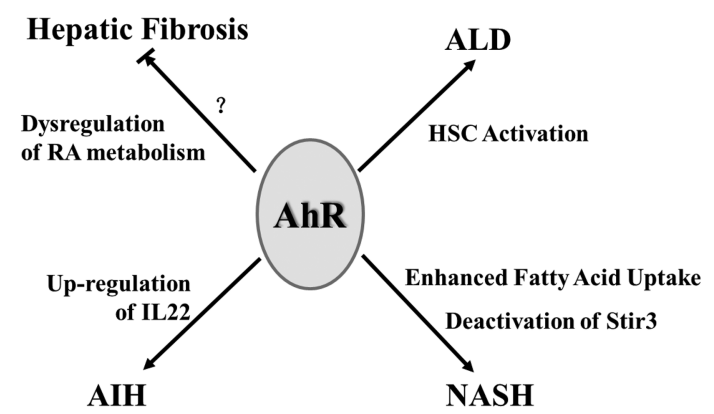

RA: retinoic acid; ALD: Alcoholic liver disease; NASH: Nonalcoholic steatohepatitis; AIH: Autoimmune hepatitis

Figure 4. Physiological role of AhR in liver tissue. AhR is highly expressed in the liver and exerts important functions in the process of liver injury. Both AhR deficiency and dioxin-induced AhR activation could result in hepatic fibrosis. Dysregulation of RA metabolism contributes to hepatic fibrosis in $\mathrm{AhR}^{-/-}$mice. Activation of $\mathrm{AhR}$ in alcohol-treated HSC indicates it might facilitate hepatic fibrogenesis in ALD. Enhanced fatty acid uptake through CD36 provokes fatty infiltration of the liver. Moreover, AhR might participate in $\mathrm{AIH}$ via regulation of several cytokines such as IL17 and IL22.

alcoholic liver disease, ${ }^{86}$ indicating that activation of AhR might play roles to facilitate hepatic fibrogenesis. Accordingly, another data showed that overexpression of AhR in liver resulted in induction of several genes including Coll $\alpha 1$ (collagen, type I, alpha 1), $\alpha$-SMA (alpha smooth muscle actin) and $\operatorname{IL} 1 \beta$, which play key roles in liver fibrogenic and proinflammatory responses. ${ }^{87}$ Thus, AhR might be a central regulatory factor in liver fibrogenesis since both loss and overexpression of AhR up-regulate liver fibrosis.

Recently, a novel role for AhR in fatty liver disease has been elucidated. A study that used transgenic mice engineered to have an allele coding for a constitutively active AhR, demonstrated induced CD36 expression and enhanced fatty acid uptake in liver cells. In accord, CD36 induction was also found in TCDD treated mice. ${ }^{88,89}$ Nonalcoholic steatohepatitis (NASH), a type of the nonalcoholic fatty liver disease (NAFLD), is caused by excessive fatty acid deposition in liver hepatocytes and characterized by liver inflammation and steatosis. It was demonstrated that AhR activation by TCDD sensitized mice fed a methionine- and choline-deficient (MCD) diet to NASH by deactivating mitochondrial sirtuin deacetylase Sirt3. ${ }^{87}$ Another study showed that MCD diet was associated with 3-fold induction of Cyplal mRNA in mouse liver and induced steatohepatitis in an AhR-dependent manner. ${ }^{90}$ In conclusion, proteins involved in fatty acid uptake, such as $\mathrm{CD} 36$, are the downstream targets of AhR, which indicates potential risks of fatty liver diseases in animals exposed to environmental dioxins.

In addition to its roles in liver fibrogenesis and steatosis, AhR is reported to up-regulate IL22 production in ConA-induced mouse hepatitis model through the Notch signaling pathway. ${ }^{57,58}$ Considering the vast amount of AhR ligands in liver, such as tryptophan metabolites, bilirubin, biliverdin, and modified low-density lipoprotein, ${ }^{91-93}$ AhR might mediate several pathways in liver diseases. Due to the high expression level of AhR in liver, the physiological roles of the receptor cannot be ignored. However, current research on the physiological roles of $\mathrm{AhR}$ in the liver is not sufficient to explain the pathogenesis of liver injury, especially the growing number of liver diseases which are associated with environmental or exogenous signals. Therefore, intensive studies of the linkage between different liver diseases and AhR activation in humans and wildlife are important for the interpretation of the pathogenesis of liver diseases and risk assessment of dioxins.

AhR in the Nervous System. Well-known dioxin interferences with the nervous system function and development are largely mediated by $\mathrm{AhR}^{94}$ As such, it was reported that chronic dietary exposure to environmentally relevant concentrations of TCDD has dose-dependent behavioral effects in trout. ${ }^{9}$ A laboratory study found that Cyplal mRNA was induced significantly in rat brain and pituitary after TCDD exposure, indicating a direct effect of TCDD on the nervous system via the AhR pathway. $^{94}$ Notably, recent evidence suggested that AhR-mediated gene response was influenced by the neuronal activity. A study using primary rat cortical neurons showed that AhR-mediated Cyplal induction was more sensitive to TCDD in active neurons during synaptogenesis compared to less active younger neurons. ${ }^{95}$ TCDD also enhanced Akt and cyclin D1 levels in HAPI microglial cells, while knockdown of AhR significantly down-regulated expression of both. ${ }^{96}$ In C. elegans, deletion of $\mathrm{AhR}^{-1}$ resulted in deficits of neuronal differentiation, evidenced by aberrant cell migration and supernumerary neuronal processes. ${ }^{97}$ These experimental findings imply important roles of AhR in TCDDinduced toxic effects and cell proliferation and differentiation in the nervous system. Further research should be performed to clarify specific that underlie roles of $\mathrm{AhR}$ in function and development of the nervous system.

New evidence from our team suggested that AhR has important physiological functions in the central nervous system by regulating the key enzyme acetylcholinesterase (AChE) in the cholinergic neurotransmission system. ${ }^{59} \mathrm{We}$ found a significant decrease in the enzymatic activity of AChE in cultured human-derived neurons treated with TCDD, while treatment with an AhR inhibitor counteracted the TCDDinduced suppression of AChE. In addition, in rat neuronal cells, which lack DREs in the AChE promoter region, suppression of AChE by TCDD was not found. Similarly, other AhR ligands such as 1,2,3,7,8-pentachlorodibenzo-p-dioxin (1,2,3,7,8PCDD), 2,3,7,8-tetrachlorodibenzofuran (2,3,7,8-TCDF), 2,3,4,7,8-pentachlorodi-benzofuran $(2,3,4,7,8-\mathrm{PCDF})$, and 2,3,7,8-tetrabromodibenzo-p-dioxin (2,3,7,8-TBDD) also suppressed neuronal AChE activity via AhR-mediated transcriptional downregulation. ${ }^{96}$ These studies provided important new insights into the mechanisms underlying a neurotransmission impairment characteristic of a number of neurodegenerative diseases. Thus, AhR emerges as an important chemoreceptor in sensing and responding to chemical signals in the nervous system.

Role of AhR Activity in Tumorgenesis. It is well documented that AhR ligands function as both carcinogens and anticarcinogens during tumorgenesis. ${ }^{19,98}$ To date, a large number of studies showed increased risks of hepatobiliary, prostate, digestive tract and breast cancers and increased frequency of hematologic neoplasms in people exposed to dioxin in the 1976 Seveso accident. ${ }^{8,99-101}$ Experimental animal studies are consistent with human epidemiologic observations and were reviewed previously. ${ }^{23,24}$ Dioxin-induced oncogene activation, oxidative stress and immunosuppression were all shown to contribute to tumorgenesis via the AhR activation. ${ }^{102}$ In the absence of exogenous ligands, intrinsic AhR signaling has an essential physiological function in carcinogenesis, as 
demonstrated in AhR null mice. ${ }^{13}$ The study showed that mice lacking AhR were more likely to develop liver tumors after exposure to diethylnitrosamine (DEN, a hepatic carcinogen), compared to the wild type mice. ${ }^{13}$ Increased expression of proliferation markers and proinflammatory cytokines such as IL6 and TNF $\alpha$ were observed in tumors of $\mathrm{AhR}^{-/-}$mice. Interestingly, constitutively generation of kynurenine (Kyn), a tryptophan catabolite that functions as an $\mathrm{AhR}$ agonist, was demonstrated in human brain tumor cells. ${ }^{103}$ Kyn was shown to suppress antitumor immune responses and promote tumor cell survival and motility through activation of AhR pathway. Thus, AhR activity and the existence of endogenous ligands in different tumor microenvironments should be investigated in future. Considering the ligand-dependent biological effects of $\mathrm{AhR}$ in the tumorgenesis, it should be possible to screen for antitumor and antimetastagenic AhR ligands which might provide additional drugs for cancer therapy. Additionally, cancer prevalence in wildlife populations should be monitored as sentinels of human health.

Other Functions. Roles of AhR and its ligands in normal physiology and in disease extend far beyond previous discussion. As such, a role for AhR in the urinary tract was recently reported in the study that $\mathrm{AhR} \mathrm{KO}$ mice had a higher risk of developing bladder stones. ${ }^{104}$ The $\mathrm{AhR}^{-/-}$mice developed urinary bladder stones first at 10 weeks of age. The stones increased in size reaching diameter of about 3 to 4 $\mathrm{mm}$ by the time the mice were 8 months old, followed by the fibrosis of the submucosal layer and a remarkable increase in the number of macrophages in the stroma of bladders in $\mathrm{AhR}^{-/-}$mice. In addition, uric acid levels in the urine of $\mathrm{AhR}^{-/-}$mice were increased 10-fold, while serum uric acid levels were not significantly different from those in the wildtype mice. The authors hypothesized that the absence of AhR caused a loss of detoxifying enzymes, leading to the accumulation of unconjugated cytokines and carcinogens in the bladder that were expected to contribute to the inflammation, as well as hyperplasia of the epithelial cell layer in the bladders of older mice. However, further studies are necessary to investigate the specific mechanisms of the AhR signaling in the urinary system impairments.

It was long known AhR is expressed in the murine retina. ${ }^{105}$ More recently, AhR was nominated as a candidate factor to play important roles in the age-related macular degeneration (AMD). $\mathrm{Hu}$ and coworkers showed that AhR expression and activity in human retinal pigment epithelial (RPE) cells decreased with age; this decrease was hypothesized to be a possible cause of AMD, since the loss of AhR not only was associated with the progressive RPE degeneration, but it also resulted in choroidal atrophy. ${ }^{106}$ Separate study found that deletion of AhR contributed to exacerbated angiogenesis and endothelial migration during choroidal neovascularization (CNV), associated with visual impairment. ${ }^{107}$ Multiple signaling pathways known to promote tumor growth, such as vascular endothelial growth factor (VEGF) and TGF $\beta$-mediated signaling ${ }^{108,109}$ were activated in $\mathrm{AhR}^{-/-}$mice. Concordant results were also observed by Kim and colleagues who showed that the $\mathrm{AhR}^{-/-}$mice exhibited subretinal accumulation of microglia and focal RPE atrophy, phenotypes observed in AMD. ${ }^{110}$ Collectively, data reviewed above showed that inactivation of AhR promotes AMD. Thus, targeting AhR could be a feasible therapeutic strategy for AMD in future. Analysis of endogenous ligands in the eye that track with AMD will be helpful to further understand the pathogenesis of AMD.

\section{DIVERSITY AND EVOLUTION OF AHR}

Phylogenetic studies in mammalian and other vertebrate and invertebrate species have demonstrated that AhR contains both bHLH and PAS homology domains. The former is involved in protein-DNA and protein-protein interaction, while the latter usually forms a secondary dimerization surface for heteromeric interactions between $\mathrm{AhR}$ and its partner proteins, such as Hsp90, ARNT and Tango.,111,112 The nematode C. elegans genome project provided the first strong evidence for an AhR homologue in invertebrates. ${ }^{3,113-115}$ The CeAhR is a 602amino acid protein that shares $38 \%$ amino acid identity with the human AhR (hAhR) over the first 395 amino acids. ${ }^{116}$ With similarity to CeAhR, the D. melanogaster AhR (DmAhR) homologue, spineless, is an 884-amino acid protein that contains a bHLH domain and a PAS domain, exhibiting $70 \%$ and $45 \%$ of the amino acid sequence conservation with mammalian AhRs, respectively. ${ }^{117}$ Similarly, mouse $\mathrm{AhR}^{\mathrm{b}-1}$ and rat $\mathrm{AhR}$ share $87 \%$ and $88 \%$ amino acid identity to the PAS domains of human AhR. ${ }^{114}$ Although it has been found that diversity in key amino acids of AhR was responsible for differential dioxin sensitivity among species, ${ }^{118,119}$ conservation of the structure of PAS domains, especially the existence of the ligand binding cavity, lays a foundation for the sensing function of $\mathrm{AhR}$ in response to environmental chemicals.

Despite differential sensitivities among different species, the AhR signaling pathway is commonly viewed as an "adaptive" response toward environmental signals, including xenobiotic agents. Currently, research has found that rudimentary PAS domains that respond to light and oxygen are present in prokaryotic light and oxygen sensors, as well as in plant photoreceptors. ${ }^{2}$ But how these PAS domains recognize the ligand is not completely understood, including the conformational structure change and interaction with other cofactors, such as chaperonins. Although sensitivity to dioxin among different species varies, ${ }^{120}$ loss of AhR not only leads to liver injury, but also immune system impairments and infertility, all of which suggest an important role of AhR in physiology and homeostasis, and further supporting an evolutionarily conserved role for this transcription factor. ${ }^{16,121,122}$

\section{ADVERSE EFFECTS OF DIOXINS IN FISH, BIRDS AND OTHER WILDLIFE SPECIES}

Despite differences in the binding affinity of AhR for dioxin and DLCs among species, adverse health effects of dioxin and DLCs have been reported for years in fish, birds and other species of wildlife that are environmentally exposed to these chemicals. $^{123,124}$ It is thought that some, if not all, of the adverse effects of dioxin, are mediated by $\mathrm{AhR}^{124}$ and most research has focused on this receptor.

It has been reported that eggs are particularly susceptible to DLCs. ${ }^{125}$ AhR mediated embryotoxicity was observed during the early life-stages of fish. ${ }^{126}$ In their study, the authors found that coexposure of embryos to PCB-126 simultaneously with the AhR antagonist and Cypla inhibitor, $\alpha$-naphthoflavone (ANF), decreased the frequency and severity of deformities, compared with embryos exposed to PCB-126 alone. To date, lake trout is the most sensitive species of fish evaluated in regard to their response to TCDD. ${ }^{127}$ Elevated levels of TCDD and related compounds in the environment were hypothesized to explain the increased mortality of lake trout sac fry in Lake Ontario during the last century. ${ }^{28}$ Although the sensitivity of zebrafish embryos to TCDD is 40 times lower compared to the 


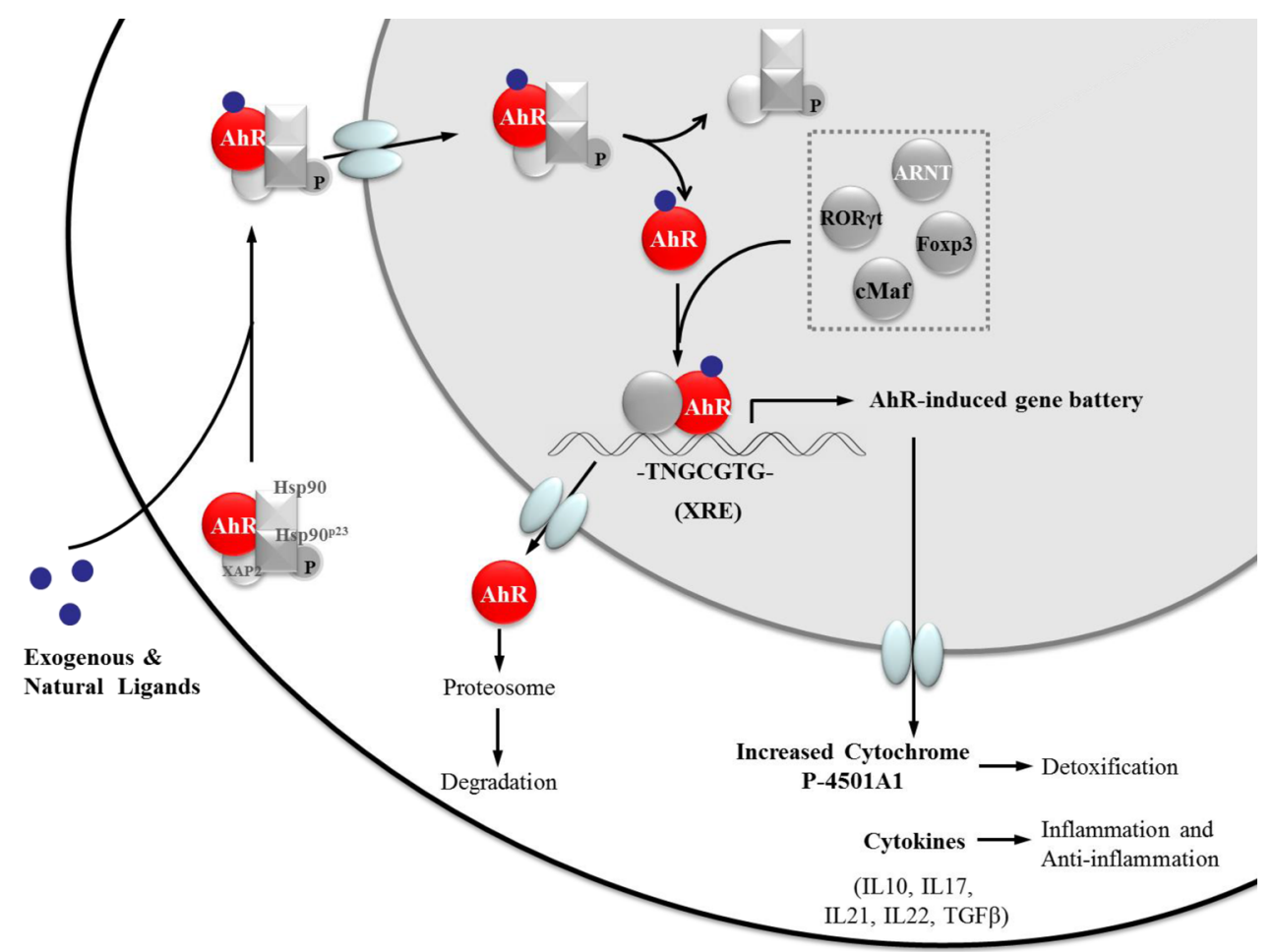

Figure 5. AhR signal transduction in function and immune regulation of immune cells. Typically, upon activation by its ligands, AhR translocates from the cytoplasm into the nucleus and exchanges its chaperones for ARNT, subsequently binds to DREs and activates transcription of downstream target genes such as Cyplal. However, AhR also participates into immune cell differentiation and cytokine secretion via binding with or initiating transcription of other nuclear transcription factors, such as cMaf, ROR $\gamma \mathrm{t}$, and Foxp3.

lake trout, functional deficits, including blood regurgitation and a striking ventricular standstill, were observed in the hearts of developing zebrafish embryos at $120 \mathrm{~h}$ post fertilization. ${ }^{129}$ Similar changes were observed in the developing heart of zebrafish embryos exposed to PCB-126, while knockdown of AhR2 by morpholino oligoes delayed and diminished the morphologically visible damage. ${ }^{130}$ Increased percentages of apoptotic cells in the dorsal midbrain of zebrafish embryos exposed to TCDD were observed and this effect was almost abolished in the presence of AhR antagonist, ANF. ${ }^{131}$ In addition, differences in the sensitivity to dioxins exist between fish and mammalian species, but these differences are of the order of more and less sensitive rodent strain differences. Thus, fish is still one of the most common and valuable animal models for ecological risk assessment, especially in the study of embryotoxicity. ${ }^{132}$

Many species of birds are also directly exposed to the environmental pollution. Chicken is the preferred model organism to study exposure in birds. In ovo studies showed that the bile, liver, kidneys, heart, and leptomeninges were the most contaminated organs of chicken embryos exposed to PAHs; in part, the bioactivity of the PAHs in these tissues was facilitated by the formation of $\mathrm{PAH}$ adducts in blood vessel endothelium. ${ }^{133}$ In chickens hatched from the PCB-126 exposed eggs, expression levels of Cypla4 mRNA in whole liver tissue increased 29-fold. ${ }^{134}$ Damage to hepatic membrane structure and function was correlated with the increased mortality in chicken embryos exposed to PCB-126. ${ }^{135}$ Species differences of birds in responses to dioxin were also reported. Species-specific responses of wild bird AhR to dioxin showed that wild black-footed albatrosses encountered a greater threat from dioxins while the jungle crow was in a relatively lower risk. $^{136}$ Domestic chicken $\mathrm{AhR}$ is much more sensitive to dioxins than that of wild birds. ${ }^{137,138}$ Researchers further observed that amino acids located at sites 324 and 380 at the AhR1 ligand-binding domain are responsible for the differential sensitivity of AhR1 expression constructs to TCDD, PeCDF and PCB-126 among 86 avian species. ${ }^{119}$ The sensitivity of AhR1 to DLCs (LD50) in studied bird species was found to be significantly correlated with in ovo toxicity assessment for these species. ${ }^{119}$ Comparison between the chicken and terns AhR sequences showed that two amino acids (Val-325 and Ala-381) in the ligand-binding domain were responsible for the reduced activity of the tern AhR, which explained the hundred-fold sensitivity difference between the two species. ${ }^{118}$ Thus, AhR polymorphism among species, especially differences in the key amino acids in the ligand-binding pocket, explain differential sensitivity of AhRs response to dioxins.

In addition to the described above effects of DLCs on diverse animal species, other adverse health effects were also detected in fish, birds, and other wildlife species exposed to DLCs. That includes immunosuppressive effects such as impairment of NK cell activity, decreased $\mathrm{T}$ cell mitogen response, delayed-type hypersensitivity and antibody responses to ovalbumin (OVA) that were found in captive harbor seals which were fed with Baltic sea herring contaminated with PCBs, PCDDs, and PCDFs. ${ }^{53,139}$ Altered B cell proliferation was detected in bluegill sunfish after $24 \mathrm{~h}$ exposure to PCB-126. ${ }^{140}$ Microarray analysis found that genes involved in the immune system processes and immune response to stimuli were the most sensitive potential targets in juvenile rainbow trout fed with TCDD (10 and $100 \mathrm{ng} \mathrm{TCDD} / \mathrm{g}$ food). ${ }^{141}$ Immunologic toxicities such as decreased immune organ mass, lymphoid cell numbers and apoptotic thymocytes were also observed in 
chicken embryos with PCB-126 exposure. ${ }^{142,143}$ Offspring from TCDD-exposed domestic chickens exhibited B cell suppression in their adulthood. ${ }^{144}$ Reduced numbers of developing lymphoid cells were observed in the thymus and bursa of bull embryos from New York Harbor contaminated with dioxins and PCBs. ${ }^{145}$ Hepatic Cypla level was induced in the wild black-footed albatross under exposure of dioxins and related compounds from the North Pacific, which indicated risks of liver injury in this population. ${ }^{146}$ The induction of Cypla-like protein was also detected in the wild population of common cormorants from Lake Biwa, Japan, which was exposed to multiple DLCs such as PCDDs, PCDFs, and PCBs. ${ }^{147}$ Laboratory studies using murine models further confirmed these toxic effects in vivo. ${ }^{53,148,149}$ However, the roles of wildlife species' AhRs in response to the environmental exposure to dioxin and DLCs are still very poorly understood. There are many challenges for the ecological risk assessment of various environmental chemicals, such as the complex environment, difficulties in collecting wildlife samples and coexposure to multiple compounds. A recently proposed adverse outcome pathway (AOP) concept for AhR can be constructively applied toward the assessment of the specific AhR-mediated toxicities of DLCs and other environmental toxins, based on different measures of the wildlife physiology (such as fertility, development, growth, survival, and reproduction). ${ }^{150}$

\section{DISCUSSION}

A wide variety of ligands, including exogenous and endogenous chemicals derived from both the environment and diet, allow $\mathrm{AhR}$ to act as a mediator in the adaptation to a multitude of different environmental conditions, with the biological response depending in large part on the ligand encountered (Figure 5). Several questions arise, such as, what are the determinants of the ligand recognition by $\mathrm{AhR}$ and how the diverse endogenous and exogenous ligands modulate various developmental events and physiologies mediated by AhR? What are the mechanisms behind the AhR's dual roles in the same signaling pathways, such as in both up-regulating and down-regulating the fibrogenesis? What are the various co-factors that enable the AhR to play so many different roles? The especially burning questions arise when the roles of AhR in immune system, such as in modulating the balance between Tregs and Th17 cells, are considered. AhR signaling might as well hold the keys to treatment of a variety of immune disorders, including autoimmune conditions and the Crohn's disease. Since AhR ligands exert effects in immunoregulation and other physiological and toxicological processes, screening of different AhR ligands, especially the natural ligands, can provide new mechanistically relevant treatments for these conditions.

Since AhR is highly expressed in cells at body surfaces, such as the skin and gut mucosa and particular in mucosal-associated lymphocytes, this molecule is perfectly positioned to be a sensor of the external environmental signals. The role of AhR in the balance of immunity and tolerance and in the control of local homeostasis has been clearly demonstrated in recent years. Deletion of AhR produced mice that were highly susceptible to infection by intestinal bacteria, exhibited altered composition of gut microbiota, impaired function and inflammatory immune activation of gut epithelium. ${ }^{25,46}$ In addition to xenobiotics, AhR ligands now include endogenous metabolites, dietary derivatives and bacterial metabolites. Thus, the crosstalk among the dietary components/xenobiotics, the $\mathrm{AhR}$ and the gut microbiome appears to be an important factor in the maintenance of the mucosal immunity. AhR activation by endogenous ligands and the following signaling response are still poorly understood. Among the questions that need to be elucidated is what the dietary and bacterial products are that might play protective or adverse roles in gut immunity by virtue of being agonists or antagonists of AhR? What is the role of AhR and AhR ligands under the different disease conditions? Since xenobiotics significantly affect the physiology and composition of the active human gut microbiome, ${ }^{153}$ identification of the bacterial species in human gut and a metabolomic analysis of the intestinal bacterial products under the xenobiotic or dietary exposures should provide important clues to understanding effects of these chemicals on the gut immunity and their potential roles as AhR ligands.

Evidence of Treg and Th17 differentiation by different AhR ligands gives us new insight into development of therapeutic avenues for autoimmune diseases. Furthermore, ligand dependent regulation of $\mathrm{T}$ cell polarization gives us directions to develop targeted drugs. However, current investigations are based mainly on animal models and the concentration of dioxin used in most studies is much higher than the environmentally relevant dose level. This raises the question of how the responses would differ with the lower dose, long-term exposures encountered by the wildlife and in human population. Additional studies of the effects of dietary patterns, particularly the foods containing putative AhR ligands, on modulation of immune functions could help us further understand the physiological role of $\mathrm{AhR}$ and aid in the development of dietary recommendations. A better understanding of the physiological and toxicological roles of AhR as a sensor of chemical signals from both the external environment and intracellular environment will enhance our understanding of how dioxins or DLCs hijack the AhR and disrupt AhRdependent signaling pathways to produce their toxicities.

Studies on the wildlife confirm that the immune system is the most sensitive target of DLCs and that this sensitivity is mediated via the AhR orthologs in the diverse species. Although immune system was developing for millions of years, many of the molecules involved in its function have conserved structures and are involved in the similar pathways in phyla as diverse as invertebrates, fish, and mammals. ${ }^{151-153}$ TGF $\beta$, Foxp3, and ROR $\gamma$, have been identified in bony fish. ${ }^{154}$ Related genes such as IL17, IL22, and IFN $\gamma$ have also been detected in avian species. ${ }^{155}$ Thus, the first application of the AOP-conceptualized study of the effects of DLCs in the wildlife should be focused on the immune functions of various environmentally endangered species. Next, data obtained in the study of the wildlife should be confirmed in the murine models and integrated with known AhR-mediated effects in humans, to provide a unified picture of the AhR signalingmediated physiologies and pathophysiologies in diverse species, to enable a better understanding of possible interventions to better both the ecology and the human health.

\section{AUTHOR INFORMATION}

\section{Corresponding Authors}

*(J.X.J) Phone: 1-916-7340329; fax: 1-916-7347908; e-mail: joyjiang@ucdavis.edu

*(B.Z.) Phone: 86-010-62842867; fax: 86-010-62842867; email: binzhao@rcees.ac.cn.

\section{Author Contributions}

All authors wrote and revised this paper. 


\section{Notes}

The authors declare no competing financial interest.

\section{ACKNOWLEDGMENTS}

This work was supported by Strategic Priority Research Program of the Chinese Academy of Sciences (XDB14030401, XDB14030402), the National Natural Science Foundation of China (Grants 21321004 and 21277168), YSW2013A01 from Chinese Academy of Sciences, and K01 DK090121 from U.S. Department of Health and Human Services (National Institutes of Health-National Institute of Diabetes and Digestive and Kidney Diseases). We thank Dr. Irina Krylova, Dr. Marjorie A. Phillips and Angela C. Zhang for discussion and comments during the manuscript preparation.

\section{ABBREVIATIONS}

$\begin{array}{ll}\text { AhR } & \text { aryl hydrocarbon receptor } \\ \text { ARNT } & \text { aryl hydrocarbon receptor nuclear translocator } \\ \text { AOP } & \text { adverse outcome pathway } \\ \text { DRE } & \text { dioxin responsive element } \\ \text { TCDD } & 2,3,7, \text {-tetrachlorodibenzo-p-dioxin } \\ \text { bHLH/PAS } & \text { basic helix-loop-helix Per-Arnt-Sim } \\ \text { HSP90 } & \text { heat shock protein 90 } \\ \text { DLCs } & \text { dioxin like compounds } \\ \text { ANF } & \alpha \text {-naphthoflavone } \\ \text { BNF } & \beta \text {-naphthoflavone } \\ \text { NASH } & \text { Nonalcoholic steatohepatitis } \\ \text { ROS } & \text { Reactive oxygen species } \\ \text { HSC } & \text { hepatic stellate cell } \\ \text { AIH } & \text { autoimmune hepatitis } \\ \text { AChE } & \text { Acetylcholinesterase } \\ \text { HAHs } & \text { halogenated hydrocarbons } \\ \text { PAHs } & \text { polycyclic aromatic hydrocarbons } \\ \text { EAE } & \text { experimental autoimmune encephalomyelitis } \\ \text { RA } & \text { retinoic acid } \\ \text { FICZ } & \text { 6-formylindolo-(3,2-b)-carbazole } \\ \text { IELs } & \text { intraepithelial lymphocytes } \\ \text { ILCs } & \text { innate lymphoid cells } \\ \text { I3C } & \text { indol-3-carbinol }\end{array}$

\section{REFERENCES}

(1) Crews, S. T. Control of cell lineage-specific development and transcription by bHLH-PAS proteins. Genes Dev. 1998, 12 (5), 607620.

(2) Gu, Y. Z.; Hogenesch, J. B.; Bradfield, C. A. The PAS superfamily: Sensors of environmental and developmental signals. Annu. Rev. Pharmacol. Toxicol. 2000, 40 (1), 519-561.

(3) Hahn, M. E. The aryl hydrocarbon receptor: A comparative perspective. Comp. Biochem. Physiol., Part C: Pharmacol., Toxicol. Endocrinol. 1998, 121 (1-3), 23-53.

(4) Hahn, M. E. Aryl hydrocarbon receptors: Diversity and evolution. Chem. Biol. Interact. 2002, 141 (1-2), 131-160.

(5) Poland, A.; Palen, D.; Glover, E. Analysis of the four alleles of the murine aryl hydrocarbon receptor. Mol. Pharmacol. 1994, 46 (5), 915921.

(6) Poland, A.; Glover, E.; Kende, A. S. Stereospecific, high affinity binding of 2,3,7,8-tetrachlorodibenzo-p-dioxin by hepatic cytosol. Evidence that the binding species is receptor for induction of aryl hydrocarbon hydroxylase. J. Biol. Chem. 1976, 251 (16), 4936-4946.

(7) Poland, A.; Glover, E. 2, 3, 7, 8-Tetrachlorodibenzo-p-dioxin: A potent inducer of $\delta$-aminolevulinic acid synthetase. Science 1973, 179 (4072), 476-477.

(8) Warner, M.; Mocarelli, P.; Samuels, S.; Needham, L.; Brambilla, P.; Eskenazi, B. Dioxin exposure and cancer risk in the Seveso
Women's Health Study. Environ. Health Perspect. 2011, 119 (12), $1700-1705$.

(9) Giesy, J. P.; Jones, P. D.; Kannan, K.; Newsted, J. L.; Tillitt, D. E.; Williams, L. L. Effects of chronic dietary exposure to environmentally relevant concentrations to 2,3,7,8-tetrachlorodibenzo-p-dioxin on survival, growth, reproduction and biochemical responses of female rainbow trout (Oncorhynchus mykiss). Aquat. Toxicol. 2002, 59 (1-2), $35-53$.

(10) Nebert, D. W.; Dalton, T. P.; Okey, A. B.; Gonzalez, F. J. Role of aryl hydrocarbon receptor-mediated induction of the CYP1 enzymes in environmental toxicity and cancer. J. Biol. Chem. 2004, 279 (23), 23847-23850.

(11) Mandal, P. K. Dioxin: A review of its environmental effects and its aryl hydrocarbon receptor biology. J. Comp. Physiol., B 2005, 175 (4), 221-230.

(12) Hahn, M. E. Dioxin toxicology and the aryl hydrocarbon receptor: Insights from fish and other non-traditional models. Mar. Biotechnol. (NY) 2001, 3 (Suppl 1), S224-S238.

(13) Fan, Y.; Boivin, G. P.; Knudsen, E. S.; Nebert, D. W.; Xia, Y.; Puga, A. The aryl hydrocarbon receptor functions as a tumor suppressor of liver carcinogenesis. Cancer Res. 2010, 70 (1), 212-220.

(14) Denison, M. S.; Pandini, A.; Nagy, S. R.; Baldwin, E. P.; Bonati, L. Ligand binding and activation of the Ah receptor. Chem. Biol. Interact 2002, 141 (1-2), 3-24.

(15) Denison, M. S.; Nagy, S. R. Activation of the aryl hydrocarbon receptor by structurally diverse exogenous and endogenous chemicals. Annu. Rev. Pharmacol. Toxicol. 2003, 43 (1), 309-334.

(16) Fernandez-Salguero, P.; Pineau, T.; Hilbert, D. M.; McPhail, T.; Lee, S. S.; Kimura, S.; Nebert, D. W.; Rudikoff, S.; Ward, J. M.; Gonzalez, F. J. Immune system impairment and hepatic fibrosis in mice lacking the dioxin-binding Ah receptor. Science 1995, 268 (5211), $722-726$.

(17) Fernandez-Salguero, P. M.; Ward, J. M.; Sundberg, J. P.; Gonzalez, F. J. Lesions of aryl-hydrocarbon receptor-deficient mice. Vet. Pathol. 1997, 34 (6), 605-614.

(18) Song, J.; Clagett-Dame, M.; Peterson, R. E.; Hahn, M. E.; Westler, W. M.; Sicinski, R. R.; DeLuca, H. F. A ligand for the aryl hydrocarbon receptor isolated from lung. Proc. Natl. Acad. Sci. U. S. A. 2002, 99 (23), 14694-14699.

(19) Jin, U. H.; Lee, S. O.; Pfent, C.; Safe, S. The aryl hydrocarbon receptor ligand omeprazole inhibits breast cancer cell invasion and metastasis. BMC Cancer 2014, 14 (498), 1-14.

(20) Lehmann, G. M.; Xi, X.; Kulkarni, A. A.; Olsen, K. C.; Pollock, S. J.; Baglole, C. J.; Gupta, S.; Casey, A. E.; Huxlin, K. R.; Sime, P. J.; Feldon, S. E.; Phipps, R. P. The aryl hydrocarbon receptor ligand ITE inhibits TGF $\beta 1$-induced human myofibroblast differentiation. Am. J. Pathol. 2011, 178 (4), 1556-1567.

(21) Schroeder, J. C.; Dinatale, B. C.; Murray, I. A.; Flaveny, C. A.; Liu, Q.; Laurenzana, E. M.; Lin, J. M.; Strom, S. C.; Omiecinski, C. J.; Amin, S.; Perdew, G. H. The uremic toxin 3-indoxyl sulfate is a potent endogenous agonist for the human aryl hydrocarbon receptor. Biochemistry 2010, 49 (2), 393-400.

(22) Pierre, S.; Chevallier, A.; Teixeira-Clerc, F.; Ambolet-Camoit, A.; Bui, L. C.; Bats, A. S.; Fournet, J. C.; Fernandez-Salguero, P.; Aggerbeck, M.; Lotersztajn, S.; Barouki, R.; Coumoul, X. Aryl hydrocarbon receptor-dependent induction of liver fibrosis by dioxin. Toxicol. Sci. 2014, 137 (1), 114-124.

(23) Murray, I. A.; Patterson, A. D.; Perdew, G. H. Aryl hydrocarbon receptor ligands in cancer: Friend and foe. Nat. Rev. Cancer 2014, 14 (12), 801-814.

(24) Safe, S.; Lee, S. O.; Jin, U. H. Role of the aryl hydrocarbon receptor in carcinogenesis and potential as a drug target. Toxicol. Sci. 2013, 135 (1), 1-16.

(25) Li, Y.; Innocentin, S.; Withers, D. R.; Roberts, N. A.; Gallagher, A. R.; Grigorieva, E. F.; Wilhelm, C.; Veldhoen, M. Exogenous stimuli maintain intraepithelial lymphocytes via aryl hydrocarbon receptor activation. Cell 2011, 147 (3), 629-640.

(26) Veldhoen, M.; Hirota, K.; Westendorf, A. M.; Buer, J.; Dumoutier, L.; Renauld, J. C.; Stockinger, B. The aryl hydrocarbon 
receptor links TH17-cell-mediated autoimmunity to environmental toxins. Nature 2008, 453 (7191), 106-109.

(27) Xu, Z.; Parra, D.; Gomez, D.; Salinas, I.; Zhang, Y. A.; von Gersdorff Jorgensen, L.; Heinecke, R. D.; Buchmann, K.; LaPatra, S.; Sunyer, J. O. Teleost skin, an ancient mucosal surface that elicits gutlike immune responses. Proc. Natl. Acad. Sci. U. S. A. 2013, 110 (32), 13097-13102.

(28) Apetoh, L.; Quintana, F. J.; Pot, C.; Joller, N.; Xiao, S.; Kumar, D.; Burns, E. J.; Sherr, D. H.; Weiner, H. L.; Kuchroo, V. K. The aryl hydrocarbon receptor interacts with c-Maf to promote the differentiation of type 1 regulatory T cells induced by IL-27. Nat. Immunol 2010, 11 (9), 854-861.

(29) Rannug, U.; Smirnova, A.; Alsberg, T.; Wincent, E.; Rannug, A. Formation and background levels of the endogenous AHR ligand FICZ in vitro and in vivo. Toxicol. Lett. 2012, 211, S14-S14.

(30) Watanabe, I.; Tatebe, J.; Namba, S.; Koizumi, M.; Yamazaki, J.; Morita, T. Activation of aryl hydrocarbon receptor mediates indoxyl sulfate-induced monocyte chemoattractant protein-1 expression in human umbilical vein endothelial cells. Circ. J. 2013, 77 (1), 224-230.

(31) Henry, E. C.; Welle, S. L.; Gasiewicz, T. A. TCDD and a putative endogenous AhR ligand, ITE, elicit the same immediate changes in gene expression in mouse lung fibroblasts. Toxicol. Sci. 2010, 114 (1), 90-100.

(32) Wang, K.; Li, Y.; Jiang, Y. Z.; Dai, C. F.; Patankar, M. S.; Song, J. S.; Zheng, J. An endogenous aryl hydrocarbon receptor ligand inhibits proliferation and migration of human ovarian cancer cells. Cancer Lett. 2013, 340 (1), 63-71.

(33) Quintana, F. J.; Murugaiyan, G.; Farez, M. F.; Mitsdoerffer, M.; Tukpah, A. M.; Burns, E. J.; Weiner, H. L. An endogenous aryl hydrocarbon receptor ligand acts on dendritic cells and $\mathrm{T}$ cells to suppress experimental autoimmune encephalomyelitis. Proc. Natl. Acad. Sci. U. S. A. 2010, 107 (48), 20768-20773.

(34) Öberg, M.; Bergander, L.; Håkansson, H.; Rannug, U.; Rannug, A. Identification of the tryptophan photoproduct 6-formylindolo [3, 2b] carbazole, in cell culture medium, as a factor that controls the background aryl hydrocarbon receptor activity. Toxicol. Sci. 2005, 85 (2), 935-943.

(35) Wincent, E.; Bengtsson, J.; Mohammadi Bardbori, A.; Alsberg, T.; Luecke, S.; Rannug, U.; Rannug, A. Inhibition of cytochrome P4501-dependent clearance of the endogenous agonist FICZ as a mechanism for activation of the aryl hydrocarbon receptor. Proc. Natl. Acad. Sci. U. S. A. 2012, 109 (12), 4479-4484.

(36) Monteleone, I.; Rizzo, A.; Sarra, M.; Sica, G.; Sileri, P.; Biancone, L.; MacDonald, T. T.; Pallone, F.; Monteleone, G. Aryl hydrocarbon receptor-induced signals up-regulate IL-22 production and inhibit inflammation in the gastrointestinal tract. Gastroenterology 2011, 141 (1), 237-248.

(37) Veldhoen, M.; Hirota, K.; Christensen, J.; O'Garra, A.; Stockinger, B. Natural agonists for aryl hydrocarbon receptor in culture medium are essential for optimal differentiation of Th17 T cells. J. Exp. Med. 2009, 206 (1), 43-49.

(38) Zhang, S.; Qin, C. H.; Safe, S. H. Flavonoids as aryl hydrocarbon receptor agonists/antagonists: Effects of structure and cell context. Environ. Health Perspect. 2003, 111 (16), 1877-1882.

(39) Zhou, J. G.; Henry, E. C.; Palermo, C. M.; Dertinger, S. D.; Gasiewicz, T. A. Species-specific transcriptional activity of synthetic flavonoids in guinea pig and mouse cells as a result of differential activation of the aryl hydrocarbon receptor to interact with dioxinresponsive elements. Mol. Pharmacol. 2003, 63 (4), 915-924.

(40) Chen, I.; Safe, S.; Bjeldanes, L. Indole-3-carbinol and diindolylmethane as aryl hydrocarbon (Ah) receptor agonists and antagonists in T47D human breast cancer cells. Biochem. Pharmacol. 1996, 51 (8), 1069-1076.

(41) Kiss, E. A.; Vonarbourg, C. Aryl hydrocarbon receptor: A molecular link between postnatal lymphoid follicle formation and diet. Gut Microbes 2012, 3 (6), 577-582.

(42) Phelan, D.; Winter, G.; Rogers, W.; Lam, J.; Denison, M. Activation of the Ah receptor signal transduction pathway by bilirubin and biliverdin. Arch. Biochem. Biophys. 1998, 357 (1), 155-163.
(43) Fang, C. C.; Chen, F. Y.; Chen, C. R.; Liu, C. C.; Wong, L. C.; Liu, Y. W.; Su, J. G. Cyprodinil as an activator of aryl hydrocarbon receptor. Toxicology 2013, 304, 32-40.

(44) Murray, I. A.; Perdew, G. H. Omeprazole stimulates the induction of human insulin-like growth factor binding protein-1 through aryl hydrocarbon receptor activation. J. Pharmacol. Exp. Ther. 2008, 324 (3), 1102-1110.

(45) O’Donnell, E. F.; Saili, K. S.; Koch, D. C.; Kopparapu, P. R.; Farrer, D.; Bisson, W. H.; Mathew, L. K.; Sengupta, S.; Kerkvliet, N. I.; Tanguay, R. L.; Kolluri, S. K. The anti-inflammatory drug leflunomide is an agonist of the aryl hydrocarbon receptor. PLoS One 2010, 5 (10), e13128.

(46) Kiss, E. A.; Vonarbourg, C.; Kopfmann, S.; Hobeika, E.; Finke, D.; Esser, C.; Diefenbach, A. Natural aryl hydrocarbon receptor ligands control organogenesis of intestinal lymphoid follicles. Science 2011, 334 (6062), 1561-1565.

(47) Qiu, J.; Heller, J. J.; Guo, X.; Chen, Z. M.; Fish, K.; Fu, Y. X.; Zhou, L. The aryl hydrocarbon receptor regulates gut immunity through modulation of innate lymphoid cells. Immunity 2012, 36 (1), 92-104.

(48) Jin, U. H.; Lee, S. O.; Sridharan, G.; Lee, K.; Davidson, L. A.; Jayaraman, A.; Chapkin, R. S.; Alaniz, R.; Safe, S. Microbiome-derived tryptophan metabolites and their aryl hydrocarbon receptor-dependent agonist and antagonist activities. Mol. Pharmacol. 2014, 85 (5), $777-788$.

(49) Zelante, T.; Iannitti, R. G.; Cunha, C.; De Luca, A.; Giovannini, G.; Pieraccini, G.; Zecchi, R.; D’Angelo, C.; Massi-Benedetti, C.; Fallarino, F.; Carvalho, A.; Puccetti, P.; Romani, L. Tryptophan catabolites from microbiota engage aryl hydrocarbon receptor and balance mucosal reactivity via interleukin-22. Immunity 2013, 39 (2), $372-385$.

(50) Moura-Alves, P.; Fae, K.; Houthuys, E.; Dorhoi, A.; Kreuchwig, A.; Furkert, J.; Barison, N.; Diehl, A.; Munder, A.; Constant, P.; Skrahina, T.; Guhlich-Bornhof, U.; Klemm, M.; Koehler, A. B.; Bandermann, S.; Goosmann, C.; Mollenkopf, H. J.; Hurwitz, R; Brinkmann, V.; Fillatreau, S.; Daffe, M.; Tummler, B.; Kolbe, M.; Oschkinat, H.; Krause, G.; Kaufmann, S. H. AhR sensing of bacterial pigments regulates antibacterial defence. Nature 2014, 512 (7515), 387-392.

(51) Bessede, A.; Gargaro, M.; Pallotta, M. T.; Matino, D.; Servillo, G.; Brunacci, C.; Bicciato, S.; Mazza, E. M.; Macchiarulo, A.; Vacca, C.; Iannitti, R; Tissi, L.; Volpi, C.; Belladonna, M. L.; Orabona, C.; Bianchi, R.; Lanz, T. V.; Platten, M.; Della Fazia, M. A.; Piobbico, D.; Zelante, T.; Funakoshi, H.; Nakamura, T.; Gilot, D.; Denison, M. S.; Guillemin, G. J.; DuHadaway, J. B.; Prendergast, G. C.; Metz, R; Geffard, M.; Boon, L.; Pirro, M.; Iorio, A.; Veyret, B.; Romani, L.; Grohmann, U.; Fallarino, F.; Puccetti, P. Aryl hydrocarbon receptor control of a disease tolerance defence pathway. Nature 2014, 511 (7508), 184-190.

(52) Alexander, C.; Rietschel, E. T. Bacterial lipopolysaccharides and innate immunity. J. Endotoxin Res. 2001, 7 (3), 167-202.

(53) Ross, P.; De Swart, R.; Addison, R.; Van Loveren, H.; Vos, J.; Osterhaus, A. Contaminant-induced immunotoxicity in harbour seals: Wildlife at risk? Toxicology 1996, 112 (2), 157-169.

(54) Nikolaidis, E. Immunotoxicity of 2,3,7,8-tetrachlorodibenzo-pdioxin and related polychlorinated aromatic hydrocarbons in birds. Acta Pharm. Nord. 1990, 2 (2), 127-128.

(55) Baccarelli, A.; Mocarelli, P.; Patterson, D. G., Jr.; Bonzini, M.; Pesatori, A. C.; Caporaso, N.; Landi, M. T. Immunologic effects of dioxin: New results from Seveso and comparison with other studies. Environ. Health Perspect. 2002, 110 (12), 1169-1173.

(56) Barouki, R; Coumoul, X.; Fernandez-Salguero, P. M. The aryl hydrocarbon receptor, more than a xenobiotic-interacting protein. FEBS Lett. 2007, 581 (19), 3608-3615.

(57) Alam, M. S.; Maekawa, Y.; Kitamura, A.; Tanigaki, K.; Yoshimoto, T.; Kishihara, K.; Yasutomo, K. Notch signaling drives IL-22 secretion in $\mathrm{CD}^{+} \mathrm{T}$ cells by stimulating the aryl hydrocarbon receptor. Proc. Natl. Acad. Sci. U. S. A. 2010, 107 (13), 5943-5948. 
(58) Xu, M.; Morishima, N.; Mizoguchi, I.; Chiba, Y.; Fujita, K.; Kuroda, M.; Iwakura, Y.; Cua, D. J.; Yasutomo, K.; Mizuguchi, J.; Yoshimoto, T. Regulation of the development of acute hepatitis by IL23 through IL-22 and IL-17 production. Eur. J. Immunol. 2011, 41 (10), 2828-2839.

(59) Xie, H. Q.; Xu, H. M.; Fu, H. L.; Hu, Q.; Tian, W. J.; Pei, X. H.; Zhao, B. AhR-mediated effects of dioxin on neuronal acetylcholinesterase expression in vitro. Environ. Health Perspect. 2013, 121 (5), 613-618.

(60) Hawrylowicz, C. M.; O'Garra, A. Potential role of interleukin10-secreting regulatory $\mathrm{T}$ cells in allergy and asthma. Nat. Rev. Immunol 2005, 5 (4), 271-283.

(61) Kremer, J. M.; Westhovens, R.; Leon, M.; Di Giorgio, E.; Alten, R.; Steinfeld, S.; Russell, A.; Dougados, M.; Emery, P.; Nuamah, I. F.; Williams, G. R.; Becker, J. C.; Hagerty, D. T.; Moreland, L. W. Treatment of rheumatoid arthritis by selective inhibition of T-cell activation with fusion protein CTLA4Ig. $N$ Engl J. Med. 2003, 349 (20), 1907-1915.

(62) Josefowicz, S. Z.; Lu, L. F.; Rudensky, A. Y. Regulatory T cells: Mechanisms of differentiation and function. Annu. Rev. Immunol. 2012, $30,531-564$.

(63) Wynn, T. A. T(H)-17: A giant step from $\mathrm{T}(\mathrm{H}) 1$ and $\mathrm{T}(\mathrm{H}) 2$. Nat. Immunol 2005, 6 (11), 1069-1070.

(64) Quintana, F. J.; Basso, A. S.; Iglesias, A. H.; Korn, T.; Farez, M. F.; Bettelli, E.; Caccamo, M.; Oukka, M.; Weiner, H. L. Control of $\mathrm{T}(\mathrm{reg})$ and $\mathrm{T}(\mathrm{H}) 17$ cell differentiation by the aryl hydrocarbon receptor. Nature 2008, 453 (7191), 65-71.

(65) Rohlman, D.; Pham, D.; Yu, Z.; Steppan, L. B.; Kerkvliet, N. I. Aryl hydrocarbon receptor-mediated perturbations in gene expression during early stages of $\mathrm{CD} 4(+) \mathrm{T}$-cell differentiation. Front Immunol 2012, 3, 223.

(66) Schulz, V. J.; Smit, J. J.; Bol-Schoenmakers, M.; van Duursen, M. B.; van den Berg, M.; Pieters, R. H. Activation of the aryl hydrocarbon receptor reduces the number of precursor and effector $\mathrm{T}$ cells, but preserves thymic $\mathrm{CD} 4^{+} \mathrm{CD} 25^{+} \mathrm{Foxp} 3^{+}$regulatory $\mathrm{T}$ cells. Toxicol. Lett. 2012, 215 (2), 100-109.

(67) Navid, F.; Bruhs, A.; Schuller, W.; Fritsche, E.; Krutmann, J.; Schwarz, T.; Schwarz, A. The aryl hydrocarbon receptor is involved in UVR-induced immunosuppression. J. Invest. Dermatol. 2013, 133 (12), $2763-2670$

(68) Spits, H.; Mjosberg, J. The aryl hydrocarbon receptor: A sentinel safeguarding the survival of immune cells in the gut. Immunity 2012, 36 (1), 5-7.

(69) Walker, J. A.; Barlow, J. L.; McKenzie, A. N. Innate lymphoid cells-how did we miss them? Nat. Rev. Immunol 2013, 13 (2), 75-87.

(70) Spits, H.; Artis, D.; Colonna, M.; Diefenbach, A.; Di Santo, J. P.; Eberl, G.; Koyasu, S.; Locksley, R. M.; McKenzie, A. N.; Mebius, R. E.; Powrie, F.; Vivier, E. Innate lymphoid cells-a proposal for uniform nomenclature. Nat. Rev. Immunol. 2013, 13 (2), 145-149.

(71) Cua, D. J.; Tato, C. M. Innate IL-17-producing cells: The sentinels of the immune system. Nat. Rev. Immunol. 2010, 10 (7), 479-489.

(72) Tait Wojno, E. D.; Artis, D. Innate lymphoid cells: Balancing immunity, inflammation, and tissue repair in the intestine. Cell Host Microbe 2012, 12 (4), 445-457.

(73) Lee, J. S.; Cella, M.; McDonald, K. G.; Garlanda, C.; Kennedy, G. D.; Nukaya, M.; Mantovani, A.; Kopan, R.; Bradfield, C. A.; Newberry, R. D.; Colonna, M. AHR drives the development of gut ILC22 cells and postnatal lymphoid tissues via pathways dependent on and independent of Notch. Nat. Immunol. 2012, 13 (2), 144-151.

(74) Yoshida, T.; Katsuya, K.; Oka, T.; Koizumi, S.; Wakita, D.; Kitamura, H.; Nishimura, T. Effects of AhR ligands on the production of immunoglobulins in purified mouse B cells. Biomed Res. 2012, 33 (2), 67-74.

(75) De Abrew, K. N.; Kaminski, N. E.; Thomas, R. S. An integrated genomic analysis of aryl hydrocarbon receptor-mediated inhibition of B-cell differentiation. Toxicol. Sci. 2010, 118 (2), 454-469.

(76) De Abrew, K. N.; Phadnis, A. S.; Crawford, R. B.; Kaminski, N. E.; Thomas, R. S. Regulation of Bach2 by the aryl hydrocarbon receptor as a mechanism for suppression of B-cell differentiation by 2,3,7,8-tetrachlorodibenzo-p-dioxin. Toxicol. Appl. Pharmacol. 2011, 252 (2), 150-158.

(77) Luu, V. P.; Vazquez, M. I.; Zlotnik, A. B cells participate in tolerance and autoimmunity through cytokine production. Autoimmunity 2014, 47 (1), 1-12.

(78) Senthilkumar, K.; Iseki, N.; Hayama, S.; Nakanishi, J.; Masunaga, S. Polychlorinated dibenzo- $p$-dioxins, dibenzofurans, and dioxin-like polychlorinated biphenyls in livers of birds from Japan. Arch. Environ. Contam. Toxicol. 2002, 42 (2), 244-255.

(79) Braune, B. M.; Simon, M. Dioxins, furans, and non-ortho PCBs in Canadian Arctic seabirds. Environ. Sci. Technol. 2003, 37 (14), 3071-3077.

(80) Pesatori, A. C.; Consonni, D.; Bachetti, S.; Zocchetti, C.; Bonzini, M.; Baccarelli, A.; Bertazzi, P. A. Short- and long-term morbidity and mortality in the population exposed to dioxin after the "Seveso accident". Ind. Health 2003, 41 (3), 127-138.

(81) Walisser, J. A.; Glover, E.; Pande, K.; Liss, A. L.; Bradfield, C. A. Aryl hydrocarbon receptor-dependent liver development and hepatotoxicity are mediated by different cell types. Proc. Natl. Acad. Sci. U. S. A. 2005, 102 (49), 17858-17863.

(82) Andreola, F.; Calvisi, D. F.; Elizondo, G.; Jakowlew, S. B.; Mariano, J.; Gonzalez, F. J.; De Luca, L. M. Reversal of liver fibrosis in aryl hydrocarbon receptor null mice by dietary vitamin A depletion. Hepatology 2004, 39 (1), 157-166.

(83) Andreola, F.; Hayhurst, G. P.; Luo, G.; Ferguson, S. S.; Gonzalez, F. J.; Goldstein, J. A.; De Luca, L. M. Mouse liver CYP2C39 is a novel retinoic acid 4-hydroxylase. Its down-regulation offers a molecular basis for liver retinoid accumulation and fibrosis in aryl hydrocarbon receptor-null mice. J. Biol. Chem. 2004, 279 (5), 34343438.

(84) Lee, Y. S.; Jeong, W. I. Retinoic acids and hepatic stellate cells in liver disease. J. Gastroenterol. Hepatol. 2012, 27 (Suppl 2), 75-79.

(85) Zhang, H. F.; Lin, X. H.; Yang, H.; Zhou, L. C.; Guo, Y. L.; Barnett, J. V.; Guo, Z. M. Regulation of the activity and expression of aryl hydrocarbon receptor by ethanol in mouse hepatic stellate cells. Alcohol.: Clin. Exp. Res. 2012, 36 (11), 1873-1881.

(86) Suh, Y. G.; Jeong, W. I. Hepatic stellate cells and innate immunity in alcoholic liver disease. World J. Gastroenterol 2011, 17 (20), 2543-2551.

(87) He, J.; Hu, B.; Shi, X.; Weidert, E. R.; Lu, P.; Xu, M.; Huang, M.; Kelley, E. E.; Xie, W. Activation of the aryl hydrocarbon receptor sensitizes mice to nonalcoholic steatohepatitis by deactivating mitochondrial sirtuin deacetylase Sirt3. Mol. Cell. Biol. 2013, 33 (10), 2047-2055.

(88) He, J.; Lee, J. H.; Febbraio, M.; Xie, W. The emerging roles of fatty acid translocase/CD36 and the aryl hydrocarbon receptor in fatty liver disease. Exp. Biol. Med. (Maywood) 2011, 236 (10), 1116-1121.

(89) Lee, J. H.; Wada, T.; Febbraio, M.; He, J.; Matsubara, T.; Lee, M. J.; Gonzalez, F. J.; Xie, W. A novel role for the dioxin receptor in fatty acid metabolism and hepatic steatosis. Gastroenterology 2010, 139 (2), 653-663.

(90) Matsubara, T.; Tanaka, N.; Krausz, K. W.; Manna, S. K.; Kang, D. W.; Anderson, E. R.; Luecke, H.; Patterson, A. D.; Shah, Y. M.; Gonzalez, F. J. Metabolomics identifies an inflammatory cascade involved in dioxin- and diet-induced steatohepatitis. Cell Metab. 2012, 16 (5), 634-644.

(91) McMillan, B. J.; Bradfield, C. A. The aryl hydrocarbon receptor is activated by modified low-density lipoprotein. Proc. Natl. Acad. Sci. U. S. A. 2007, 104 (4), 1412-1417.

(92) Oo, Y. H.; Hubscher, S. G.; Adams, D. H. Autoimmune hepatitis: New paradigms in the pathogenesis, diagnosis, and management. Hepatol. Int. 2010, 4 (2), 475-493.

(93) Quintana, F. J.; Sherr, D. H. Aryl hydrocarbon receptor control of adaptive immunity. Pharmacol Rev. 2013, 65 (4), 1148-1161.

(94) Huang, P.; Rannug, A.; Ahlbom, E.; Hakansson, H.; Ceccatelli, S. Effect of 2,3,7,8-tetrachlorodibenzo-p-dioxin on the expression of cytochrome P450 1A1, the aryl hydrocarbon receptor, and the aryl 
hydrocarbon receptor nuclear translocator in rat brain and pituitary. Toxicol. Appl. Pharmacol. 2000, 169 (2), 159-167.

(95) Lin, C. H.; Juan, S. H.; Wang, C. Y.; Sun, Y. Y.; Chou, C. M.; Chang, S. F.; Hu, S. Y.; Lee, W. S.; Lee, Y. H. Neuronal activity enhances aryl hydrocarbon receptor-mediated gene expression and dioxin neurotoxicity in cortical neurons. J. Neurochem. 2008, 104 (5), $1415-1429$.

(96) Xu, H. M.; Xie, H. Q.; Tao, W. Q.; Zhou, Z. G.; Li, S. Z.; Zhao, B. Dioxin and dioxin-like compounds suppress acetylcholinesterase activity via transcriptional downregulations in vitro. J. Mol. Neurosci. 2014, 53 (3), 417-423.

(97) Qin, H.; Powell-Coffman, J. A. The Caenorhabditis elegans aryl hydrocarbon receptor, AHR-1, regulates neuronal development. Dev. Biol. 2004, 270 (1), 64-75.

(98) DiNatale, B. C.; Smith, K.; John, K.; Krishnegowda, G.; Amin, S. G.; Perdew, G. H. Ah receptor antagonism represses head and neck tumor cell aggressive phenotype. Mol. Cancer Res. 2012, 10 (10), 1369-1379.

(99) Chang, E. T.; Boffetta, P.; Adami, H. O.; Cole, P.; Mandel, J. S. A critical review of the epidemiology of Agent Orange/TCDD and prostate cancer. Eur. J. Epidemiol. 2014, 29 (10), 667-723.

(100) Bertazzi, P. A.; Zocchetti, C.; Guercilena, S.; Consonni, D.; Tironi, A.; Landi, M. T.; Pesatori, A. C. Dioxin exposure and cancer risk: A 15-year mortality study after the "Seveso accident". Epidemiology 1997, 8 (6), 646-652.

(101) Bertazzi, A.; Pesatori, A. C.; Consonni, D.; Tironi, A.; Landi, M. T.; Zocchetti, C. Cancer incidence in a population accidentally exposed to 2,3,7,8-tetrachlorodibenzo-para-dioxin. Epidemiology 1993, 4 (5), 398-406.

(102) Ridolfi, R.; Cozzolino, R.; Boscaino, F.; Malorni, L.; Canzanella, S.; Malorni, A.; Palmieri, G.; Malorni, L. AhR (aryl hydrocarbon receptor) polymorphisms: A possible role in TCDD (dioxins)-AhR binding and carcinogenesis. Int. J. Biol. 2014, 6 (4), 8295.

(103) Opitz, C. A.; Litzenburger, U. M.; Sahm, F.; Ott, M.; Tritschler, I.; Trump, S.; Schumacher, T.; Jestaedt, L.; Schrenk, D.; Weller, M.; Jugold, M.; Guillemin, G. J.; Miller, C. L.; Lutz, C.; Radlwimmer, B.; Lehmann, I.; von Deimling, A.; Wick, W.; Platten, M. An endogenous tumour-promoting ligand of the human aryl hydrocarbon receptor. Nature 2011, 478 (7368), 197-203.

(104) Butler, R.; Inzunza, J.; Suzuki, H.; Fujii-Kuriyama, Y.; Warner, M.; Gustafsson, J. A. Uric acid stones in the urinary bladder of aryl hydrocarbon receptor (AhR) knockout mice. Proc. Natl. Acad. Sci. U. S. A. 2012, 109 (4), 1122-1126.

(105) Jain, S.; Maltepe, E.; Lu, M. M.; Simon, C.; Bradfield, C. A. Expression of ARNT, ARNT2, HIF1 alpha, HIF2 alpha and Ah receptor mRNAs in the developing mouse. Mech. Dev. 1998, 73 (1), $117-123$.

(106) Hu, P.; Herrmann, R.; Bednar, A.; Saloupis, P.; Dwyer, M. A.; Yang, P.; Qi, X.; Thomas, R. S.; Jaffe, G. J.; Boulton, M. E.; McDonnell, D. P.; Malek, G. Aryl hydrocarbon receptor deficiency causes dysregulated cellular matrix metabolism and age-related macular degeneration-like pathology. Proc. Natl. Acad. Sci. U. S. A. 2013, 110 (43), E4069-E4078.

(107) Choudhary, M.; Kazmin, D.; Hu, P.; Thomas, R. S.; McDonnell, D. P.; Malek, G. Aryl hydrocarbon receptor knock-out exacerbates choroidal neovascularization via multiple pathogenic pathways. J. Pathol. 2015, 235 (1), 101-112.

(108) Goel, H. L.; Mercurio, A. M. VEGF targets the tumour cell. Nat. Rev. Cancer 2013, 13 (12), 871-882.

(109) Pickup, M.; Novitskiy, S.; Moses, H. L. The roles of TGF $\beta$ in the tumour microenvironment. Nat. Rev. Cancer 2013, 13 (11), 788799.

(110) Kim, S. Y.; Yang, H. J.; Chang, Y. S.; Kim, J. W.; Brooks, M.; Chew, E. Y.; Wong, W. T.; Fariss, R. N.; Rachel, R. A.; Cogliati, T.; Qian, H.; Swaroop, A. Deletion of aryl hydrocarbon receptor AHR in mice leads to subretinal accumulation of microglia and RPE atrophy. Invest. Ophthalmol. Visual Sci. 2014, 55 (9), 6031-6040.
(111) Dolwick, K. M.; Swanson, H. I.; Bradfield, C. A. In vitro analysis of Ah receptor domains involved in ligand-activated DNA recognition. Proc. Natl. Acad. Sci. U. S. A. 1993, 90 (18), 8566-8570.

(112) Huang, Z. J.; Edery, I.; Rosbash, M. PAS is a dimerization domain common to Drosophila period and several transcription factors. Nature 1993, 364 (6434), 259-262.

(113) Wilson, R.; Ainscough, R.; Anderson, K.; Baynes, C.; Berks, M.; Bonfield, J.; Burton, J.; Connell, M.; Copsey, T.; Cooper, J.; et al. $2.2 \mathrm{Mb}$ of contiguous nucleotide sequence from chromosome III of $\mathrm{C}$. elegans. Nature 1994, 368 (6466), 32-38.

(114) Hahn, M. E.; Karchner, S. I.; Shapiro, M. A.; Perera, S. A. Molecular evolution of two vertebrate aryl hydrocarbon (dioxin) receptors (AHR1 and AHR2) and the PAS family. Proc. Natl. Acad. Sci. U. S. A. 1997, 94 (25), 13743-13748.

(115) Consortium, C. e. S. Genome sequence of the nematode C. elegans: A platform for investigating biology. Science 1998, 282 (5396), 2012-2018.

(116) Powell-Coffman, J. A.; Bradfield, C. A.; Wood, W. B. Caenorhabditis elegans orthologs of the aryl hydrocarbon receptor and its heterodimerization partner the aryl hydrocarbon receptor nuclear translocator. Proc. Natl. Acad. Sci. U. S. A. 1998, 95 (6), 28442849.

(117) Duncan, D. M.; Burgess, E. A.; Duncan, I. Control of distal antennal identity and tarsal development in Drosophila by spinelessaristapedia, a homolog of the mammalian dioxin receptor. Genes Dev. 1998, 12 (9), 1290-1303.

(118) Karchner, S. I.; Franks, D. G.; Kennedy, S. W.; Hahn, M. E. The molecular basis for differential dioxin sensitivity in birds: Role of the aryl hydrocarbon receptor. Proc. Natl. Acad. Sci. U. S. A. 2006, 103 (16), 6252-6257.

(119) Farmahin, R.; Manning, G. E.; Crump, D.; Wu, D.; Mundy, L. J.; Jones, S. P.; Hahn, M. E.; Karchner, S. I.; Giesy, J. P.; Bursian, S. J.; Zwiernik, M. J.; Fredricks, T. B.; Kennedy, S. W. Amino acid sequence of the ligand-binding domain of the aryl hydrocarbon receptor 1 predicts sensitivity of wild birds to effects of dioxin-like compounds. Toxicol. Sci. 2013, 131 (1), 139-152.

(120) Mimura, J.; Fujii-Kuriyama, Y. Functional role of AhR in the expression of toxic effects by TCDD. Biochim. Biophys. Acta 2003, 1619 (3), 263-268.

(121) Pocar, P.; Fischer, B.; Klonisch, T.; Hombach-Klonisch, S. Molecular interactions of the aryl hydrocarbon receptor and its biological and toxicological relevance for reproduction. Reproduction 2005, 129 (4), 379-389.

(122) Robles, R.; Morita, Y.; Mann, K. K.; Perez, G. I.; Yang, S.; Matikainen, T.; Sherr, D. H.; Tilly, J. L. The aryl hydrocarbon receptor, a basic helix-loop-helix transcription factor of the PAS gene family, is required for normal ovarian germ cell dynamics in the mouse. Endocrinology 2000, 141 (1), 450-453.

(123) Connor, K. T.; Aylward, L. L. Human response to dioxin: Aryl hydrocarbon receptor (AhR) molecular structure, function, and doseresponse data for enzyme induction indicate an impaired human AhR. J. Toxicol. Environ. Health, Part B 2006, 9 (2), 147-171.

(124) Hotchkiss, A. K.; Rider, C. V.; Blystone, C. R.; Wilson, V. S.; Hartig, P. C.; Ankley, G. T.; Foster, P. M.; Gray, C. L.; Gray, L. E. Fifteen years after "Wingspread"-environmental endocrine disrupters and human and wildlife health: Where we are today and where we need to go. Toxicol. Sci. 2008, 105 (2), 235-259.

(125) Ankley, G. T.; Tillitt, D. E.; Giesy, J. P. Maternal transfer of bioactive polychlorinated aromatic hydrocarbons in spawning chinook salmon (Oncorhynchus tschawytscha). Mar. Environ. Res. 1989, 28 (1), $231-234$.

(126) Wassenberg, D. M.; Di Giulio, R. T. Synergistic embryotoxicity of polycyclic aromatic hydrocarbon aryl hydrocarbon receptor agonists with cytochrome P4501A inhibitors in Fundulus heteroclitus. Environ. Health Perspect. 2004, 112 (17), 1658-1664.

(127) Elonen, G. E.; Spehar, R. L.; Holcombe, G. W.; Johnson, R. D.; Fernandez, J. D.; Erickson, R. J.; Tietge, J. E.; Cook, P. M. Comparative toxicity of $2,3,7,8$-tetrachlorodibenzo-p-dioxin to 
seven freshwater fish species during early life-stage development. Environ. Toxicol. Chem. 1998, 17 (3), 472-483.

(128) Cook, P. M.; Robbins, J. A.; Endicott, D. D.; Lodge, K. B.; Guiney, P. D.; Walker, M. K.; Zabel, E. W.; Peterson, R. E. Effects of aryl hydrocarbon receptor-mediated early life stage toxicity on lake trout populations in Lake Ontario during the 20th century. Environ. Sci. Technol. 2003, 37 (17), 3864-3877.

(129) Antkiewicz, D. S.; Burns, C. G.; Carney, S. A.; Peterson, R. E.; Heideman, W. Heart malformation is an early response to TCDD in embryonic zebrafish. Toxicol. Sci. 2005, 84 (2), 368-377.

(130) Jonsson, M. E.; Jenny, M. J.; Woodin, B. R.; Hahn, M. E.; Stegeman, J. J. Role of AHR2 in the expression of novel cytochrome P450 1 family genes, cell cycle genes, and morphological defects in developing zebra fish exposed to $3,3^{\prime}, 4,4^{\prime}, 5$-pentachlorobiphenyl or 2,3,7,8-tetrachlorodibenzo-p-dioxin. Toxicol. Sci. 2007, 100 (1), 180193.

(131) Dong, W.; Teraoka, H.; Yamazaki, K.; Tsukiyama, S.; Imani, S.; Imagawa, T.; Stegeman, J. J.; Peterson, R. E.; Hiraga, T. 2,3,7,8tetrachlorodibenzo- $p$-dioxin toxicity in the zebrafish embryo: Local circulation failure in the dorsal midbrain is associated with increased apoptosis. Toxicol. Sci. 2002, 69 (1), 191-201.

(132) Ankley, G. T.; Villeneuve, D. L. The fathead minnow in aquatic toxicology: Past, present and future. Aquat. Toxicol. 2006, 78 (1), 91102.

(133) Granberg, L.; Brunstrom, B.; Brandt, I. Formation of benzo[a]pyrene and 7,12-dimethylbenz[a]anthracene adducts in vascular endothelia of cytochrome P4501A-induced chicken embryos. Environ. Toxicol. Chem. 2003, 22 (10), 2393-2399.

(134) Head, J. A.; O’Brien, J.; Kennedy, S. W. Exposure to 3,3',4,4',5Pentachlorobiphenyl during embryonic development has a minimal effect on the cytochrome P4501a response to 2,3,7,8-Tetrachlorodibenzo-p-dioxin in cultured chicken embryo hepatocytes. Environ. Toxicol. Chem. 2006, 25 (11), 2981.

(135) Katynski, A. L.; Vijayan, M. M.; Kennedy, S. W.; Moon, T. W. 3,3',4,4',5-Pentachlorobiphenyl (PCB 126) impacts hepatic lipid peroxidation, membrane fluidity and beta-adrenoceptor kinetics in chick embryos. Comp. Biochem. Physiol., Part C: Toxicol. Pharmacol. 2004, 137 (1), 81-93.

(136) Iwata, H.; Kim, E.-Y. Risk assessment of dioxins in wild birds by the combination of contamination level and species-specific response of aryl hydrocarbon receptor. Interdiscip. Stud. Environ. Chem. 2010, 4, 105-112.

(137) Kennedy, S. W.; Lorenzen, A.; Jones, S. P.; Hahn, M. E.; Stegeman, J. J. Cytochrome P4501A induction in avian hepatocyte cultures: A promising approach for predicting the sensitivity of avian species to toxic effects of halogenated aromatic hydrocarbons. Toxicol. Appl. Pharmacol. 1996, 141 (1), 214-230.

(138) Hoffman, D. J.; Melancon, M. J.; Klein, P. N.; Eisemann, J. D.; Spann, J. W. Comparative developmental toxicity of planar polychlorinated biphenyl congeners in chickens, American kestrels, and common terns. Environ. Toxicol. Chem. 1998, 17 (4), 747-757.

(139) Ross, P. S.; De Swart, R. L.; Reijnders, P. J.; Van Loveren, H.; Vos, J. G.; Osterhaus, A. D. Contaminant-related suppression of delayed-type hypersensitivity and antibody responses in harbor seals fed herring from the Baltic Sea. Environ. Health Perspect. 1995, 103 (2), $162-167$.

(140) Duffy, J. E.; Zelikoff, J. T. The relationship between noncoplanar PCB-induced immunotoxicity and hepatic CYP1A induction in a fish model. J. Immunotoxicol. 2006, 3 (1), 39-47.

(141) Liu, Q.; Rise, M. L.; Spitsbergen, J. M.; Hori, T. S.; Mieritz, M.; Geis, S.; McGraw, J. E.; Goetz, G.; Larson, J.; Hutz, R. J.; Carvan, M. J. Gene expression and pathologic alterations in juvenile rainbow trout due to chronic dietary TCDD exposure. Aquat. Toxicol. 2013, 140, 356-368.

(142) Fox, L. L.; Grasman, K. A. Effects of PCB 126 on primary immune organ development in chicken embryos. J. Toxicol. Environ. Health, Part A 1999, 58 (4), 233-244.
(143) Goff, K. F.; Hull, B. E.; Grasman, K. A. Effects of PCB 126 on primary immune organs and thymocyte apoptosis in chicken embryos. J. Toxicol. Environ. Health, Part A 2005, 68 (6), 485-500.

(144) Peden-Adams, M.; Alonso, K.; Godard, C.; Skipper, S.; Mashburn, W.; Hoover, J.; Charbonneau, C.; Henshel, D.; Dickerson, R. Effects of environmentally relevant concentrations of 2,3,7,8-TCDD on domestic chicken immune function and CYP450 activity: F1 generation and egg injection studies. Chemosphere 1998, 37 (9-12), $1923-1939$.

(145) Grasman, K. A.; Echols, K. R.; May, T. M.; Peterman, P. H.; Gale, R. W.; Orazio, C. E. Immunological and reproductive health assessment in herring gulls and black-crowned night herons in the Hudson-Raritan Estuary. Environ. Toxicol. Chem. 2013, 32 (3), 548561.

(146) Kubota, A.; Watanabe, M.; Kunisue, T.; Kim, E. Y.; Tanabe, S.; Iwata, H. Hepatic CYP1A induction by chlorinated dioxins and related compounds in the endangered black-footed albatross from the North Pacific. Environ. Sci. Technol. 2010, 44 (9), 3559-3565.

(147) Kubota, A.; Iwata, H.; Tanabe, S.; Yoneda, K.; Tobata, S. Hepatic CYP1A induction by dioxin-like compounds, and congenerspecific metabolism and sequestration in wild common cormorants from Lake Biwa, Japan. Environ. Sci. Technol. 2005, 39 (10), 36113619.

(148) Huff, J.; Lucier, G.; Tritscher, A. Carcinogenicity of TCDD: Experimental, mechanistic, and epidemiologic evidence. Annu. Rev. Pharmacol Toxicol 1994, 34, 343-372.

(149) Smialowicz, R. J.; Riddle, M. M.; Williams, W. C.; Diliberto, J. J. Effects of 2,3,7,8-tetrachlorodibenzo-p-dioxin (TCDD) on humoral immunity and lymphocyte subpopulations: Differences between mice and rats. Toxicol. Appl. Pharmacol. 1994, 124 (2), 248-256.

(150) Ankley, G. T.; Bennett, R. S.; Erickson, R. J.; Hoff, D. J.; Hornung, M. W.; Johnson, R. D.; Mount, D. R.; Nichols, J. W.; Russom, C. L.; Schmieder, P. K.; Serrrano, J. A.; Tietge, J. E.; Villeneuve, D. L. Adverse outcome pathways: A conceptual framework to support ecotoxicology research and risk assessment. Environ. Toxicol. Chem. 2010, 29 (3), 730-741.

(151) Janeway, C. A. Jr, T, P., Walport, M, Shlomchik, M. J. Immunobiology: The Immune System in Health and Disease; Garland Science: New York, 2001.

(152) Cooper, M. D.; Alder, M. N. The evolution of adaptive immune systems. Cell 2006, 124 (4), 815-822.

(153) Maurice, C. F.; Haiser, H. J.; Turnbaugh, P. J. Xenobiotics shape the physiology and gene expression of the active human gut microbiome. Cell 2013, 152 (1-2), 39-50.

(154) Weaver, C. T.; Hatton, R. D. Interplay between the TH17 and TReg cell lineages: A (co-)evolutionary perspective. Nat. Rev. Immunol. 2009, 9 (12), 883-889.

(155) Matulova, M.; Havlickova, H.; Sisak, F.; Babak, V.; Rychlik, I. SPI1 defective mutants of Salmonella enterica induce cross-protective immunity in chickens against challenge with serovars Typhimurium and Enteritidis. Vaccine 2013, 31 (31), 3156-3162. 